\title{
SOVEREIGN WeALTh Fund Portfolios
}

\author{
Alexander Dyck, \\ University of Toronto, Rotman School of Management \\ Adair Morse", \\ University of Chicago, Booth School of Business
}

December, 2011

\begin{abstract}
This paper examines objectives driving Sovereign Wealth Fund (SWF) investments using a novel, handcollected dataset of their investments in public equities, private firms, and real estate. SWF public statements suggest two primary objectives: a financial portfolio investor objective, seeking to maximize risk adjusted returns through assembling diversified holdings; and a developmental objective, seeking to use SWF investments to influence the domestic development path. We test for the explanatory power of these objectives using a model of portfolio choice and ownership stakes. Long-horizon benchmarks and risk hedging variables do have explanatory power in the panel and time series of allocations across asset class, industry and geography. However, we find that sovereign ownership of SWFs matter. Nearly half of the portfolio choice explanatory power comes from variables that capture development agendas. An ownership stake model predicts that SWF investments should include sufficient stakes for the transfer of knowledge. We find results that the distribution of active-sized stakes correlate with developmental agendas, particularly in specific industries. The results of significant heterogeneity across SWFs in their objectives, and the power of development objectives provides new predictions for the potential impact of SWF investments.
\end{abstract}

\footnotetext{
* We thank John Cochrane, Magnus Dahlquist, Patrick Bolton, Paola Sapienza, and seminar participants at London Business School, Imperial College London, CEPR/Gerzensee summer institute, Emory, Yale, and University of Chicago for helpful comments. Dyck thanks INSEAD for hosting him as a visiting scholar while part of this research was completed. Morse thanks the James S. Kemper Family Foundation, CRSP, the Initiative on Global Markets and the Polsky Center for Entrepreneurship for financial support.
} 
Sovereign Wealth Funds (SWFs) are an important new class of risk-taking institutional investors. These state investment vehicles have existed for many decades, but an acceleration in their growth in the mid-2000s resulted in two dozen funds controlling \$3 trillion in assets (GAO 2008). Does it matter that sovereigns control the investment of so much capital?

It could be that SWFs are just like other institutional investors with the only important difference being their longer time horizon given the absence of any near term liabilities. This perspective is encouraged by SWFs, in particular by the SWF signatories to the Santiago Principles, who affirm that SWFs "aim to maximize risk adjusted financial returns." Alternatively, sovereignty may imply that SWFs are a distinct class of institutional investors, with sovereign objectives producing different portfolio allocations and therefore a potentially different impact.

A first goal in this paper is to assemble, to the extent possible, a complete picture of SWF portfolios across risky asset classes and allow these data to paint a picture of what sovereignty means for allocation and control. Prior research has had difficulty addressing this question. Challenges in accessing data have limited the literature to focus primarily on SWFs' international holdings of publicly traded companies and on the subset of more transparent SWFs, where sovereign objectives may be less likely to be seen.

Through manual searches in primary media, we uncover many more investments than observable through the mainstream databases, particularly holdings of private equity and real estate. We then do case-study-like analysis for each investment to determine the inflows and outflows and construct time series valuation for all of their asset holdings, including private equities and real estate. We perform this analysis for all important sovereign wealth funds from 1999-2008, including the less transparent Middle Eastern and Asian funds. We include all funds with more than $\$ 10$ billion in assets as of 2007 , which results in 20 funds averaging $\$ 116$ billion per fund with $\$ 2.03$ trillion in assets under management and

\footnotetext{
${ }^{1}$ Generally Accepted Principles and Practice ('Santiago Principles) Number 19, http://www.iwgswf.org/pubs/gapplist.htm.
} 
$\$ 1.43$ trillion in risky assets under management as of 2008 . These holdings comprise $87 \%$ of the rough estimates from the market.

With this compilation of holdings, we present a number of tabulation results. We document extensive non-public holdings. SWFs allocate only half of their risky portfolio mix (by allocation percent) to public equities, the remainder to private equities, predominantly private companies and LP positions (29\%) and real estate (19\%). We find a pronounced home bias. SWFs collectively own $6.4 \%$ and $4.3 \%$ of the public equity capitalizations in the Middle East and Asia respectively, while only $2 \%$ of world market capitalization. We find significant positions in certain industries, particularly a few in which they hold a large fraction of world capitalization. And we find that SWFs invest actively (we use stakes over five percent to signify active investments) in both public and private sectors but primarily in their home regions and in the industries of finance, transportation and telecommunications. Eighty percent of investment value in Asia and the Middle East are invested actively.

The primary goal of the paper is to go beyond the descriptive and test for the importance of alternative objectives in explaining the now-observable portfolio allocations and distributions of control rights in SWF investments. Objectives are not only interesting in explaining existing portfolios; rather, objectives should influence future allocations, provide insight into SWF management of investments, and likely explain responses to economic shocks. We construct our tests against what we believe to be the most plausible objectives, namely the two objectives that the sovereigns themselves articulate in their public statements.

The first stated objective of SWFs is that they maximize risk-adjusted returns. We call this the portfolio investor hypothesis. It predicts that SWFs will diversify their risky portfolios across industries and geographies, including limits on ownership concentration. As long horizon investors, SWFs will hold 
a mix of the world public market equity portfolio as well as diversified holdings in real estate and private equities. $^{2}$

The fact that SWFs are sovereign raises the possibility that the SWFs could use their portfolios to pursue objectives beyond those considered in conventional portfolio optimization. The primary alternative hypothesis is a developmental hypothesis. This is a hypothesis that SWFs will, in effect, act as sovereign development funds using their portfolios to try to alter their nation's developmental path. This developmental interest undoubtedly has both economic and political motivations, but what is important for our purposes is that it provides predictions for specific industrial and geographic focus to SWF portfolios.

An important reason why we focus on this alternative objective is that in public statements, SWF leaders often express concerns for domestic economic development. The resource wealth that supports inflows to the SWF in many countries also produces a highly focused industrial mix. A way to diversify domestic production is for SWFs to use their current financial portfolios to attempt to influence the nation's longer-term industrial mix. For a developmental agenda to be social welfare maximizing, the intervention needs to be targeted on market failures. One possibility is of "big push" externalities, in which case state-led investment can stimulate and coordinate private sector investments. This suggests SWF financed investments in industries that can hold-up other businesses and/or are central to the production process. Another possible source of market failure is of weaknesses in knowledge transfer in the industries where countries may want to diversify. SWF ownership of foreign and domestic businesses can potentially ease knowledge transfer and help in the coordination of decision making.

To be clear, in testing for the explanatory power of this developmental hypothesis we are not making any assumptions about the optimality of this choice. There are undoubtedly alternative mechanisms to achieve developmental objectives, and deviating from financial objectives opens up

\footnotetext{
${ }^{2}$ SWFs could also hold other alternatives including hedge funds and derivative products. In practice, we do not observe many such holdings as of 2008 and thus focus on the risky asset classes of public equity, private equity and real estate.
} 
discretion for political actors. Industrial planning could just be a convenient mask for investment motivated by more mundane personal political objectives, or could be done inefficiently and waste opportunities for both financial and economic returns. SWFs might also, in addition, be pursuing other political objectives. In this paper we set aside such questions for another day. Our goal here is more modest and foundational. To make such questions interesting, we need first to establish to what extent portfolios differ from that of portfolio investors and whether they can be explained by developmental objectives.

The first set of tests for the power of portfolio and developmental objectives is based on an estimation of a portfolio choice model, following most closely Massa and Siminov (2006). We focus only on risky asset classes (public and private equity, real estate). SWFs were constructed to be the risky portion of sovereigns' overall portfolios and to incorporate the fixed income holdings that SWFs do hold would entail analyzing the entire fixed income holdings on the government balance sheet. Such an analysis would entail incorporating the stability objectives of central banks, for example, and is beyond the scope of this paper. However, we do include the total government fixed income holdings in central banks and the SWF as a covariate determining the risk preferences within the risky allocations.

The dependent variable in our portfolio choice model is the SWF (risky) portfolio weight in an asset class-industry-geography "bin" (thirteen industries crossed with seven world regions and three asset classes). Our goal is in some sense is to determine the explanatory power of the set of benchmarks (a ' $r$ squared' perspective). We are more interested in how much of the variation in portfolio weights we can explain with our portfolio and developmental hypotheses variables than in how large a particular coefficient is. To this end, we have an unbalanced panel of SWF portfolios over the 1999-2008 period, which we equally weight in the analysis. Portfolios are highly autocorrelated for any SWF. We conduct our analysis first by clustering to be cognizant of our observation count, but importantly we are able to identify results off the time series aspect of portfolios, as well as the cross section. Our main results include an AR1 term such that we identify effects off the changes in portfolio weights. 
In tests of the power of portfolio investor objectives to explain actual SWF portfolios we use world capitalization as our first explanatory variable. Since we are interested in SWFs overall equity portfolios that include non-public (e.g. real estate) as well as public equities, the measure of world capitalization we use includes public and non-public equities. Potential weaknesses of this measure, coming from imprecise measurement or incomplete understanding of constraints that give rise to patterns among financial investors (such as home bias) leads us to include as an additional explanatory variable the actual portfolios of a comparison group of institutional investors. For this comparison group we also seek to capture potential deviations in the portfolio coming from a long time horizon that may affect demand for liquidity. As our comparison group we choose similarly large investors (similar minimum size as our criteria for SWFs) and that among institutional investors arguably have longer-term objectives (defined benefit pension plans). To complete our parsimonious characterization of financial portfolio objectives we also include measures to capture background risks arising from the sources for SWF wealth that create hedging motives in their financial portfolios. ${ }^{3}$

To flesh out the developmental hypothesis, we identify empirical measures to capture the potential importance of developmental objectives and include them as explanatory variables to see to what extent they can explain variation in SWFs portfolios. Our first measure is industries identified ex ante in national strategic plans. Many but not all nations that create SWFs have such plans where they identify specific industries they would like to develop, often as part of an 'economic cluster' strategy. Our second measure is an ex ante measure of industries that are most likely to be impacted by market failure, and therefore where there is potential economic grounds for government intervention, derived from OECD data. Our third measure identifies industries where those responsible for the SWF have had prior exposure, and where they believe as a result they may have a comparative advantage.

\footnotetext{
${ }^{3}$ As Merton (1982) makes clear in the case of endowments, the optimal financial portfolio should take into account risks arising from the endowment source. With SWFs, many rely on natural resource income (e.g. the revenue source is a percentage of oil revenue) so they implicitly have as a background risk variability in oil revenue and recognition of this would drive pure portfolio investors to hedge their oil exposure in their financial portfolios.
} 
As a second parallel test of whether portfolio investor or developmental objectives drive SWF choices we examine the size of ownership stakes and if they differ across industries and geographies. If SWFs act solely as simple portfolio investors, then diversification requires a larger number of small stakes, rather than concentrated positions, and there are no specific predictions that ownership concentration will be greater in one particular industry or geography. In contrast, the developmental objective requires concentrated positions in specific industries. Concentration is required as state owners need to have control rights in firms to address coordination or information failures.

What do we find? Our empirical results suggest that to understand SWFs as an institutional investor group one needs to consider their choices driven both by portfolio investor objectives and by developmental objectives. Sovereignty matters. Measures to capture portfolio investor and developmental objectives produce an r-squared of $14.4 \%$, and ignoring either dramatically reduces explanatory power. Of this explained variation, developmental objective measures accounts for $45 \%$. We disentangle the explanatory power of financial portfolio and developmental objective variables for each fund and decompose the r-squared based on the objective (discarding the covariance). For some funds (e.g. Alaska, GIC Singapore and Norway Global), measures of financial portfolio objectives capture almost all of the explained variance. In contrast, for Singapore Temasek, the Investment Corporation of Dubai, Kuwait and China as well as for most of the smaller SWFs, developmental objectives account for over half of the variation. This heterogeneity across SWFs suggests it is misleading to put all SWFs into the same category.

Focusing in on the specific coefficient estimates in our tests of financial and developmental objectives provides further insights. Prior research has not found that portfolio investors hedge their background risks. Our initial tests that do not control for developmental objectives repeat this 'nonfinding', but once we allow for developmental objectives, we do find hedging. Specifically SWFs tilt their financial portfolios (i.e. industry- geography allocations) to reduce covariance of SWF returns with 
important domestic drivers of wealth. We are among the first portfolio choice papers to identify such hedging of covariance risk for any investor class.

We find all three measures of developmental objectives have explanatory power. An indicator for industries highlighted in national (not SWF) strategic plans, is positive and significant in every specification. Inclusion in a strategic plan implies investing $135 \%$ more in the domestic industry from the naïve equal weighting. A one standard deviation larger perceived market failure score associates with SWFs investing $72 \%$ more in the domestic and $45 \%$ more in the regional industry-asset class bins. Finally, SWFs invest more in industries in which they have perceived skill. Having one standard deviation larger perceived skill associates with $238 \%$ more allocations to that industry in home country than predicted by the naïve equal weight.

Recognizing the importance of developmental objectives provides an explanation for the otherwise puzzling decisions to pursue active management and to focus active ownership positions across industries and geographies. We test for the power of developmental measures to explain variations across industries and geographies in ownership stakes, consistent with goals of extracting information, and/or applying skill. We regress the average ownership stake in an asset class-industry-region on the fraction of the variation explained by state planning objectives, in a model with industry, geography, and asset class fixed effects. A one standard deviation increase in the fraction of the portfolio choice model explained by developmental objectives implies an increase in the ownership stake by approximately $12 \%$.

In sum, the portfolio choice tests and ownership stake tests paint a consistent picture: to understand SWFs as an institutional investor group one needs to consider their choices driven both by portfolio investor objectives and by developmental objectives. The most transparent funds like Norway that pursue relatively pure portfolio investor objectives are simply not representative of the group as a whole. For many SWFs, developmental objectives play a parallel role, and for some this is a more significant factor. Developmental objectives predict a sustained tilt to their portfolios, a level of active management and different responses to economic shocks than by just focusing on features such as their 
size and their long-term focus. The significant fraction of assets devoted towards achieving developmental objectives suggests scaling downward expectations of the resources available for SWFs to engage in long horizon investing elsewhere in the world.

The power of developmental objectives in explaining portfolio choice suggest one avenue through which politics influences SWF choices. This is not however the type of political decisions raised by many critics of SWF investment policies. Our paper thus offers a different interpretation of deviations from financial objectives than offered by many in the media that voice concerns over unspecified political-economic objectives. The potential opportunity cost of such an approach is left for future work.

This paper is complementary to a growing literature on sovereign wealth funds. A number of papers have focused on SWF investments in international public equities (e.g. Bortolotti, Fotak, Megginson and Miracky (2009), Kotter and Lel (2008), Dewenter, Han and Malatesta (2008), and Fernandes (2009)) and have used this data to document industry and geographical focus as well as testing for potential agency costs by correlating proxies for fund governance with short and long window returns around announced SWF investments. Bernstein, Lerner and Schoar (2009) have focused on a set of private investments by SWF, and have exploited the timing of these investments and their implied returns to test for political, developmental and agency agendas. The main finding is weakness in SWF returns and a negative correlation between fund governance and returns, concluding that the evidence is least consistent with a developmental objective. Our paper differs from these in using a larger set of investments (simultaneously considering international and domestic traded equities, private equities, investments in private equity and real estate), in exploring tilts in these broader portfolios, as well as considering and testing for the empirical importance of economic objectives that predict tilt in portfolios. This provides more nuanced conclusions about SWFs that capture some of the important heterogeneity across these funds. In focusing on portfolios, our paper is closer to Chhaochharia and Laeven (2008), with important distinctions being that we are looking at their full portfolio rather than restricting attention 
to their international holdings of public equities, our investigation of a much larger (and different set) of SWFs and our consideration of a wide range of economic motivations for explaining portfolio choices.

The rest of the paper is organized as follows. Section I describes the data for constructing the SWF portfolios and summarizes the overall portfolio values. Section II presents a theoretical frame introducing the two alternative objectives and the empirical measures we use to capture these objectives. Section III reports our methodology for the portfolio choice and ownership stakes tests. In section IV we report results and discuss implications in section $\mathrm{V}$ we conclude.

\section{SWF Sample and Portfolio Data}

\section{I.1. SWF Sample}

To examine the portfolios of SWFs we first have to specify a SWF sample. We distinguish SWFs from a number of state-owned entities that are also active in global financial markets. For example, central banks tasked with stabilization accumulate and invest foreign exchange reserves, often in international fixed income. State-owned operating companies use profits to extend operations worldwide through acquisitions. State-owned pension funds accumulate savings from individuals and invest, generally conservatively, to ensure sufficient liquidity to cover pensioner liabilities. SWFs belong to none of these categories; they are instead state-owned investment companies, claiming a long time horizon and consequently the ability to invest across a range of asset classes.

To capture these distinctions in our data collection we restrict our attention to those state-owned investment vehicles that satisfy a commonly used definition in the literature (the Monitor Group definition of a sovereign wealth fund, included as appendix A). For reasons we describe below, we restrict our attention to the risky portfolios that we define to exclude fixed income and to funds with significant investments, which we classify as having at least $\$ 10$ billion in assets under management in 
public reports as of 2007. These requirements lead us to focus on 20 funds that we identify in Table $1 .^{4}$ While limited in number, these funds account for almost all of the money in SWFs; namely, \$2.33 trillion in end-of-year 2008 wealth according to Preqin (2009), even including the losses of that year. Although the holdings are large, the sample of funds is relatively small; thus, we ensure in our analysis that we identify objectives off the time series of investments as well as the cross section.

Funds in our sample are the largest, most important and widely recognized SWFs. These include old funds, such as the Kuwait Investment Authority, that had its origins back in 1953, as well as recently formed funds such as the China Investment Corporation, founded in 2007. These funds differ not only in age, but also in the primary source of wealth. Many funds, particularly in the Middle East, and the few western funds from Norway and Alaska, rely on wealth arising from natural resource extraction. Others use foreign currency reserves from trade surpluses as well as the transfer of wealth with legacy stateowned companies as the basis for their funds savings, most notably Asian funds such as Singapore's Temasek and Singapore's GIC. We do not employ any filter based on ex ante transparency, which across funds is low. ${ }^{5}$ A few funds (e.g., Norway and Alaska) do disclose their holdings, but these are the exception rather than the rule. Even among high transparency-ranked funds (e.g., Singapore's Temasek), transparency does not imply a disclosure of the fund's portfolio.

\section{I.2. Sources for Portfolio Data}

We use a large number of sources to assemble portfolio holdings. We start at the most direct source, the SWF itself. Like many other investors, SWFs are not required to disclose their portfolios, but they nonetheless do provide some useful information. They sometimes report the corporate structure, including the important investments. Often they report their holdings in public equity that exceed

\footnotetext{
${ }^{4}$ Abu Dhabi Investment Authority (ADIA), Abu Dhabi Investment Council (ADIC), Alaska Permanent Reserve Fund, Bahrain Mumtalakat Fund, China Investment Corporation (CIC), Dubai Holdings, Dubai World, Government of Singapore Investment Corporation (GIC), International Petroleum Investment Corporation of Abu Dhabi (IPIC), Investment Corporation of Dubai, Kuwait Investment Authority (KIA), Khazanah Nasional of Malaysia, Libya Investment Authority (LIA), Mubadala Development of Abu Dhabi, Norway Government Pension Fund- Local, Norway Government Pension Fund - Global, Qatar Investment Authority (QIA), and Temasek Holdings of Singapore.

${ }^{5}$ Two of the more commonly used measures of transparency are the Linaburg Maduaell transparency scores, available at swfinstitute.com and the Truman governance scores (Truman, 2007, 2008).
} 
thresholds defined by regulatory agencies in some countries, as this information will become known through public filings. They also often disclose ownership in select domestic private endeavors (such as building projects) and holdings that derive from their founding such as stakes in previously state-owned entities, although this information rarely includes valuations. Such information is inevitably incomplete, ignoring holdings below reporting requirements, providing only a partial indication of the extent of their private holdings.

Next, we complement this public disclosure from the SWF by accessing a range of other information from data collection companies and public filings, many of them regional, to flesh out additional investment subsidiaries and ultimately their public and private holdings. While the holdings that are not disclosed are not transparent or easily accessible, we found that a great number of them are not totally under the radar of public knowledge. We take advantage of the global data providers Capital IQ and Thompson One Banker, but our real discovery comes, especially in the case of domestic and regional public, in accessing local sources such as The Business Times of Singapore and AME and Zawya (both Middle Eastern business sources). Such providers report holdings of private companies by name, in many cases with ownership stakes. They also often provide additional information of investment companies associated with each SWF, allowing us to define a tree of investment subsidiaries associated with each SWF parent.

With the information both from the SWF and the international and regional data providers in hand, we then perform a historical case study on each subsidiary and company identified in our earlier searches using international news sources (such as Factiva) and local news sources. Going back in time allows us to produce our panel data as most information aggregators only provide current information. The case study not only helps us to identify additional companies, it allows us to fill-in missing ownership stakes and transaction histories. By combining this data with stock market data from Datastream, we construct a time series value for all public companies holdings. Equally important, we use the time series of ownership of private companies, properties, and private equity fund investments as 
an input into our valuation of private companies that we describe in more detail below. We spend significant attention on gathering enough information to identify, value and determine the ownership stake in private investments as for investments in public equities. Because the reconstruction of the portfolios has been a lengthy process, we relegate details of these efforts to the appendix.

\section{I.3. SWF Portfolio Summary Statistics}

Table 1 summarizes the results of this data collection effort for $2008^{6}$, showing that we have identified investments accounting for 2.04 trillion. This is just 13 percent less than market estimates of 2.33 trillion that likewise have to deal with very limited disclosure (columns 1-2). Our calculated total is based on more than 26,000 unique companies and even more transactions (we have multiple transactions for many companies) in public equities, private equities and real estate. While we have undoubtedly missed some investments, such as derivative products, small private holdings and hedge fund investments, these data are to our understanding the most comprehensive accounting of SWF investments available to date.

Columns 3, 4, 6, and 7 of Table 1 break down our 2.04 trillion estimate along four dimensions. Column 3 reports the value in the risky portfolio in public equities, private equities and real estate for which we know the individual investments. Column 4 reports public equity investments which we know to be indexed; we infer the industry and geography of these investments by utilizing decompositions of global and local market indexes. Column 5 lists the number of individual companies, private equity funds and properties used in arriving at these totals for risky investments, with a much greater number coming from Alaska and Norway, who hold broadly diversified portfolios. Column 6 reports our estimate of fixed income holdings, and column 7, hedge funds/other alternatives . To produce these last two columns we use either the exact amounts when provided or can be inferred from public statements (e.g. Alaska, Norway, CIC, Libya), or we take the value of the risky assets we identify and infer "up" the fixed income and alternatives amounts based on market estimates of asset class exposure. Because fixed income

\footnotetext{
${ }^{6}$ We have all years from 1998-2008; the choice of presenting 2008 figures in Table 1 is just for clarity of exposition.
} 
holdings may be used for stabilization purposes, or are close substitutes for other government funds in central banks that are used for such purposes, we do not consider them in the analysis of risky portfolios to which we now turn our attention. ${ }^{7}$

We identify portfolios by their risky asset class, and within that asset class by their industry and their geography. To simplify discussion, we refer to the asset class-industry-geography "bin" as $b$, with three asset classes (private equity, public equity, real estate), seven geographies (six world regions and one designated as 'home country') and thirteen industries for the equities asset classes and just one industry for real estate. Thus, at most there are $2 \times 7 \times 13+1 \times 7=189$ bins in which a SWF can invest its risky portfolio. Ultimately, we set up a simple portfolio choice problem, in which we test whether the weight SWF owners choose for a "bin" is driven by financial portfolio objectives adjusted to incorporate non-financial income risk variables and/or by development objectives.

\section{Theoretical Frame: SWF Objectives \& their Measurement}

What objectives are SWFs seeking to maximize? We gain some insight into this question by examining public statements from those SWFs that provide information on their objectives. These statements give strong support for a view that SWFs are driven by financial portfolio investor objectives. The Norwegian Government Pension Fund, for example, states "The Fund shall be safely managed based on the objective of high return subject to moderate risk."1 Similar language is employed by less transparent funds. The Abu Dhabi Investment Authority, states “ADIA's decisions are based solely on its economic objectives of delivering sustained long-term financial returns.” The China Investment Corporation states in its annual report that "Our mission is to make long-term investments that maximize risk-adjusted financial returns for the benefit of the State, our shareholder." This view is reinforced by the SWFs that have agreed to the "Santiago principles" where one of the "Generally accepted principles and

\footnotetext{
${ }^{7}$ Another problem with including fixed income in the analysis is that we would need to incorporate country-wide fixed income holdings. A case in point is China: any fixed income held by the China Investment Corporation must be taken as a temporary holding since the whole point of CIC is to diversify the country's massive foreign exchange, fixed income holdings into equities.
} 
practices" affirms that SWFs "aim to maximize risk adjusted financial returns." the objectives of SWFs according to many in the financial community. ${ }^{9}$

But, this is not the only objective that emerges from reading SWF statements. As Ang (2010) emphasizes, SWFs state ownership makes their management fundamentally different from ordinary investment management companies, and to maintain legitimacy they need to attend to wider political and economic factors. Public statements of some SWFs are clear that what might be termed developmental concerns influence their decision making. For example, Mubadala, an Abu Dhabi SWF states: "Mubadala is a catalyst for economic diversification of Abu Dhabi." ${ }^{10}$ It has bought stakes in foreign companies, and/or established domestic joint ventures with the desire to exploit foreign firms' knowledge and skill and bring them to bear for domestic development purposes. Or consider the statement of the objectives behind the largest CIC controlled holding that "was established to invest exclusively in domestic state-owned financial institutions on behalf of the state in order to improve governance and preserve and enhance the value of state-owned financial assets." ${ }^{11}$ Such objectives are not necessarily at odds with the Santiago principles, as they could be justified on economic grounds, and the principles allow for a reporting requirement for alternative objectives. ${ }^{12}$

Both the financial portfolio objectives and developmental objectives generate predictions for portfolio allocations and ownership stakes and allow us to assemble benchmark portfolio allocations.

\section{II.1. Financial Portfolio Investor Objective}

\footnotetext{
${ }^{8}$ Generally Accepted Principles and Practice ('Santiago Principles) Number 19, http://www.iwgswf.org/pubs/gapplist.htm.

${ }^{9}$ For example, "At the end of the day, sovereign wealth funds are just institutional investors that look to make returns for their shareholders," Hani Kablawi, Bank of New York Mellon Corp, Dec 7, 2009

${ }^{10}$ Mubadala Annual Report 2008.

${ }^{11}$ This industrial planning perspective has been underemphasized in the academic literature, but has not been ignored in policy-oriented papers (e.g. Santiso (2009)).

${ }^{12}$ GAAP Subprincipl 19.1: "If investment decisions are subject to other than economic and financial considerations, these should be clearly set out in the investment policy and be publicly disclosed."
} 
Standard portfolio theory suggests that the risky portfolio of long horizon investors should be diversified across asset classes, industries, and geographies. We construct two benchmarks to capture what a long-horizon portfolio might optimally look like. The first is a world capitalization benchmark, constructed as the proportion of world capitalized value in each asset class-geography-industry bin. SWFs claim to be long horizon investors, capable of holding assets for an indefinite period, so the benchmark includes less liquid investable private equity and real estate in addition to public equities.

For public equities, we use the market valuation of all traded companies in Datastream, aggregated to industry and country for each year. ${ }^{13}$ To calculate investable real estate, we take advantage of a model used by practicing asset managers. In particular, we apply the Prudential Real Estate Investors' (2010) model in which investable real estate is valued across geographies and over time as: Value of Real Estate $=45 \% \times$ GDP $\times(\text { GDH/Threshold GDH })^{\wedge} 1 / 3$, where GDH is per capita GDP and threshold GDP is, for countries with less than the threshold GDP, defined as \$20,000 in 2000 and adjusted for inflation.

To our knowledge there is no global investable private equity benchmark. To calculate global private equity capitalization, we thus propose an approach to construct one. Our approach recognizes that: (i) industry compositions differ by country; (ii) propensities of industries to be privately held differ by country, with the US distinctly different; (iii) valuations reflect industry characteristics and a discount for being private.

The steps in constructing the global private equity benchmark are as follows. We assemble European data to get a direct estimate of investible private equity, as disclosure requirements of tax authorities in Europe allow for meaningful estimates of private companies. Specifically, we download company revenues for all active private companies in the Bureau Van Dijk - Orbis database for Europe. ${ }^{14}$ We restrict our attention to those companies with revenue of $\$ 1$ million using this dollar limit to define an investable company. For each company identified in the first step, we produce an implied valuation. We

\footnotetext{
${ }^{13}$ We do not adjust for free float, under the assumption that even the controlled blocks could be accessible to an investor with a long time horizon. There are no material differences in results if we do not make this correction.

${ }^{14} \mathrm{We}$ use hand and computer searches to avoid duplicate companies and companies that are not investable (e.g. the Post Office which is 100 percent state-owned).
} 
use revenue multiples, allowing the revenue multiple to vary by industry. ${ }^{15}$ We calculate the worldwide public equities revenue multiple by industry, using all public companies in Datastream. We then scale the industry multiple down such that the weighted average multiple matches the private firm revenue multiple of 0.70, calculated in Moskowitz and Vissing-Jorgensen (2002) for the year 1998. We allow this multiple to grow over time with the growth rate of public equities global industry-specific multiples. This approach thus produces an estimate of the private equity capitalization by industry for Europe.

We then expand the private equity capitalization benchmark to the rest of the world. To do this, we calculate the ratio of the value of investable private companies to public companies by industry for Europe and apply this ratio to the value of public companies in each country. For example, we might find that in Europe the valuation of private companies in industry $\mathrm{X}$ is 2 billion and of public equities is 3 billion in year 2003, producing a ratio of 2/3. In Egypt then we would apply this ratio of $2 / 3$ to the public equities in the same industry in that year (say 30 million) to arrive at an estimate of Egyptian private equities in that industry and year of 20 million.

When we aggregate across all industries and over time, we estimate that the capitalization of private companies is 2.5 times public equities in Europe. Although we have no good comparison, the number appears to be reasonable. For the US where public markets play a larger role, we take advantage of Moskowitz and Vissing-Jorgensen (2005) who calculated a lower ratio of private-to-public equity capitalization of 0.79 public equities, and adjust all of the industry ratios downward to this scale, while keeping their industry-specific ranking. The advantage of our willingness to make these estimates is that they provide a picture of investable equities across industries, geographies and time. The cost is that this is admittedly an approach with measurement error.

While conceptually a world capitalization benchmark is very appealing, it also has weaknesses in capturing the portfolios of actual investors. One well known weakness is a home bias in investing arising for currency reasons or because of institutional constraints or preferences. Another potential weakness

\footnotetext{
${ }^{15}$ In principle, valuation could be done using other accounting variables, but data limitations restrict us to focusing on revenue multiples.
} 
with world capitalization is that SWF investment horizons may not actually be as long as implied by using capitalized values of investable private equity and real estate.

As a second financial portfolio benchmark that can address these weaknesses we use the actual portfolios of an international sample of defined benefit pension plans selected using the same size criteria of over $\$ 10$ billion in assets as of 2007 as in our SWF sample. ${ }^{16}$ These large defined benefit pension plans have the ability to invest in longer horizon investments, given their long-term liabilities. Through CEM benchmarking, we have annual data on asset allocation for these plans across their risky portfolios, including quite detailed information on private equities and real estate, as well as broad geography of the holding, allowing us to construct the same detailed industry-geography "bins" as we use for the SWF data. ${ }^{17}$ It is important to control for size in constructing this benchmark as Dyck and Pomorski (2010) show that even controlling for other factors, such as immediate liquidity needs, size is associated with greater percentage allocations to less liquid alternative assets. ${ }^{18}$

Another attractive feature of this benchmark for our purposes is that pension funds are home country biased. Having the home bias be a feature of the pension benchmark allows our tests of developmental agenda be conservative, and not an artifact of just picking up a typical home bias. To implement the home bias benchmark, we need to home bias the portfolio specifically for each SWF. In other words for example, the SWFs of Singapore should have a pension benchmark that over-allocates all

\footnotetext{
${ }^{16}$ Only four investor groups - family offices, endowments/foundations, defined benefit pension funds and life insurers - are potentially comparable to SWFs in their time horizon (WEF 2011). Of these, the group of comparable size with accessible data and longest duration liability profile is defined benefit pension plans.

${ }^{17} \mathrm{CEM}$ benchmarking is a Toronto based consultancy that is a leading provider of benchmark information to large pensions including the large American plans CalPERS and CalSTRS, the large Canadian plans CPPIB and Ontario Teachers, and the large European plans PGGM and APG. The CEM data have been used in a number of recent papers including French's AFA presidential address (2009) as well as Dyck and Pomorski (2010) and Bauer and Frehen (2008)), Within public equities and real estate, CEM has information on the geographic breakdown of assets to the United States, EAFE (Europe, Australia and Far East) and emerging markets. Within these geographies, most funds indicate that they benchmark to the MSCI index for that region. We infer their effective holdings of individual companies (and thus countries and industries) using IShares portfolios as a measure of MSCI indexes, which are designed to track the MSCI indexes with minimal tracking error. As a measure of the industry and geographic mix of private equity investment, we apply the annual private equity fund geography and industry distributions from Capital IQ.

${ }^{18}$ When we construct these portfolios on a sort of plans with small retiree liabilities relative to assets, our portfolios look materially the same.
} 
asset classes to Singapore and the same for the Emirates, China, Norway, etc. Thus, we need to take the observed portfolios of the pension funds in CEM, figure out how much of the portfolios represent home bias and take this home bias out, and then re-home bias each benchmark to the country of the SWF. Our best detail of the country of origin of the pension funds (we do not know the names of the pension funds in CEM) is for Canada. We assume the Canadian plan home bias is typical for pension plans and apply this bias to the allocations, specific for each SWF.

\section{II.2 Adjusting Financial Portfolio for Non-Financial Income Risk}

These two financial portfolio benchmarks may be insufficient to characterize financial investor objectives because SWF portfolio decisions theoretically should be influenced by non-financial income risk or by other risk-appetite shifters, such as wealth or fixed income holdings of the government as a whole. This section lays out the non-financial income risk adjustments and then other adjustments related to wealth and sovereign fixed income holdings as a whole.

Following Guiso, Jappelli, and Terlizzese (1996), Heaton and Lucas (2000), Vissing-Jorgensen (2002), and Massa and Siminov (2006), an investor's portfolio choice should incorporate two types of non-financial income risk adjustments. First, investors should decrease risk appetite in proportion to how much variance their own income process has, and second, investors should adjust portfolios away from risky sectors covarying with their own income process return risk.

To capture the potential impact of non-financial income risk for SWFs, we need to be precise as to their income process. While there is variation across SWFs, a general feature that influences flows to the SWFs is the success of their resource 'endowments' that generate risky flows to the SWFs. (This frame allows us to build off the work of Bodie, Merton and Samuelson (1992).) In some countries SWFs are by law entitled to a percentage of excess income from oil extraction, but, more generally, SWF flows are captured by 'excess' fiscal revenues. To remain general, we use fiscal revenues as the income flow measure and fiscal revenues as a percentage of GDP as the return on the endowment of resources. When the industries in a country do well, they pay taxes, and since the more important sectors account for more 
of the fiscal revenue, the 'return' in fiscal revenues/GDP will reflect the exposure of a government to the underlying industry market returns.

Our measure of the variance of the income process is thus the standard deviation of fiscal revenues. Because our portfolio choice model is about the choice of which risky assets to hold (and not risky-versus-risk free), any appetite for risk variable should be interacted with a "beta" for the risk of the industry-geography bin. For public equity companies, we calculate the beta risk as the monthly beta on the industry-geography portfolio of all companies in Datastream. For real estate, we use a beta of 0.5 from Linneman (2006). For private equity, we multiply the public equity beta for each industry-geography bin by an estimate of the higher risk in private equities, using 1.73 from Hall and Woodward (2007) ${ }^{19}$.

At least as important is the covariance adjustment that we define as the correlation of fiscal revenues as a percentage of GDP with the industry-region bin annual return. The industry-region bin return is the value-weighted return for all Datastream companies falling in the industry-geography bin. The prediction is that for SWFs whose fiscal revenues rely, for example, on oil prices will invest less in industries whose returns vary with oil prices. To capture both the standard deviation and covariance, we use a 19 year rolling average, annual series.

We need to scale the non-financial income adjustment variables in proportion to how important non-financial income for the SWF is relative to financial income. For an individual investor, one approach is to make sure the present value of future labor income risk is hedged in proportion to how important it is vis-à-vis the stock of financial wealth. For a SWF, we calculate the financial wealth stock based on the value of all public equities, private equities and real estate in the portfolio. For non-financial wealth, we need to value the portion of the endowment of resources that produces flows to the SWF. Following the endowment literature, we use the capitalized value of current cash flows into the SWF. ${ }^{20}$

\footnotetext{
${ }^{19}$ There are a wide variety of estimates of private equity betas. As a robustness check we re-estimate results using no adjustment to the public equity betas.

${ }^{20}$ The endowment literature uses the capitalized value of expected future donations as another source of wealth (Merton, 1992; Dimmock, 2009). We approximate cash flows using a moving average of the cash flows into the
} 
Thus we scale the non-financial income risk variables by capitalized endowment value divided by overall wealth (endowments plus financial holdings).

These risk adjustments assume that the owner of the SWF just considers in their calculations the assets owned by the SWF and their expected income from fiscal revenues. Technically, the owner of the SWF is the sovereign, and it possesses a range of other resources and obligations. We make one additional modification to risk appetite adjustments to reflect this reality, allowing for other 'wealth' held by the state to influence risk adjustments. Depending on the nature of the utility function, overall investor wealth can change portfolio allocation preferences (Merton, 1992). SWFs in countries with more sovereign wealth (e.g. China's possession of significant foreign exchange reserves) might have a greater appetite for risk in their SWF portfolios. Thus, we include a country wealth variable, calculated as the sum of the SWF wealth (that from the financial portfolio and the implied wealth from the capitalized flows) plus the amount of fixed income held in foreign reserves with the central bank. We scale the wealth effect variable relative to the overall SWF portfolio value and interact it with the beta for the bin (as described above) to gauge whether the wealth of a country increases risk appetite. Relatedly, the final adjustment variable is the the amount of fixed income held, in both the SWF and foreign reserves, relative to the overall SWF portfolio value, also multiplied times the bin beta. Table 2 presents summary statistics of our dependent variable and all of the explanatory variables used in the analysis.

\section{II.3 Developmental Objectives}

The financial investor perspective described in II.1 ignores an essential feature of SWFs - they are owned by the state. As Ang (2010) emphasizes, to maintain legitimacy they need to attend to wider political and economic factors. Consistent with this concern, Rauh and Hochberg (2011) find that in making private equity investments, U.S. public pension plans are overweight to private equity investments in their state. SWFs may be even more closely linked to the state, in that, lacking any near

SWF for three years centered on the current year. We capitalize the cash flows into a wealth stock by dividing by 0.10 . 
term requirement to make disbursements to citizens, they may feel more compelled to attend to political and economic concerns with their investments.

The desire to use a sovereign wealth fund to pursue developmental objectives can be rationalized on social welfare grounds, although it need not be driven by such logic. For a developmental agenda to be social welfare maximizing, one needs to make market failures or public goods arguments. One possibility is of "big push" externalities, whereby state-led investment can act stimulate and coordinate private sector investments (e.g., Rosenstein-Rodan (1943), Rodrick (1996), Rodriguez-Clare (1996), Morck (2011)). This suggests SWF financed investments in industries that can hold-up other businesses and/or are central to production. Another possible source of market failure is of weaknesses in knowledge transfer, particularly around knowledge central to the industries where countries may want to diversify. SWF ownership of foreign and domestic businesses can potentially ease knowledge transfer and help in the coordination of decision making.

To gauge to what extent developmental objectives explain SWF portfolios, we need to construct measures to enter the portfolio choice estimation model. The idea of our first developmental measure is to capture the sectors identified ex ante in national (not SWF) strategic plans. Many, but not all, nations in our SWF sample have such plans in which they identify specific industries they would like to develop, often as part of an 'economic cluster' strategy. After locating the repository for government documents for each country, we use the strategic plan that predates our data. Our measure is an industry-level dummy variable, indicating which industries are targeted in a SWF plan. These plans tend to feature 'vertical' industries targeted for development, as well as industries like finance and telecommunications, that are viewed as infrastructure aimed to promote development across a set of industries. In most cases, the targeted industries are only domestic, but in the case of Singapore, some of the planning is regional. We provide summary stats for this variable in Table 2.

The idea motivating our second development measure is to use an economically motivated measure of sectors that can be specified ex ante to be susceptible to market failure. We propose a 
measure that takes advantage of the OECD Indicators of Regulation Impact data, described in Conway and Nicoletti (2006). The data are based on two inputs. The first is the degree of regulation of that important industries face within a country and year, with the idea being that the greater the regulation the more ex ante market failure based grounds for intervention. The OECD constructs this measure based on factors leading to or correlated with market failure such as industry concentration, barriers to entry, etc. The second input is each industry's exposure to these market failures based on input-output needs, capturing what the OECD developers of the index term a 'knock-on' effect of market failure and regulation across a wider set of industries. The regulation impact data thus produces a dynamic measure of distortions existing across the full range of industry sectors and countries. ${ }^{21}$

An ideal industry market failure index for SWFs would only be based on data from countries where intervention is driven by economic reasons, rather than for political or ideological reasons. Rajan and Zingales (1998), using similar logic, focused just on the US as a benchmark for their measure of external finance. We use US regulatory impact data and that of New Zealand, Australia and Canada. We use this expanded set of countries to capture the possibility that the extent of market failure in industries may also depend on the extent of the market, and these smaller countries are similar to the US in the limited tradition of state ownership and historical rigidities that may influence industry structure. Specifically, we take an average of the coefficients for New Zealand, the United States, Australia and Canada, using the weighted (to market capitalization) average of ISIC codes for these countries for our industry set.

It may also be that SWF owners not only believe in these traditional market failures, but that it is possible to possess superior skills or information about particular industries. For a number of countries, the initial endowment of the SWF includes state-owned enterprises (that may or may not be partially privatized). This close proximity to industries may lead SWF managers to believe they have superior

\footnotetext{
${ }^{21}$ The OECD produces this regulatory impact measure for three categories: all firms, for publicly-owned firms, and for non-publicly owned firms. We use the measure for non-publicly owned firms which is very highly correlated with the measure for all firms..
} 
information or skill about the industry, and they may seek to exploit this in their investment patterns, producing a geographic or industry tilt to their portfolios. For example, Temasek of Singapore was given the state's stake in Singapore airlines, and Temasek's subsequent investments in a series of airlines in the region could be related to a perceived ability and knowledge in this sector. This argument is closely related to the explanation offered for the patterns of investing in Massa and Siminov (2006).

To capture this idea we construct a third development measure labeled Perceived Skill. Construction of this variable takes advantage of the fact that we have information on the ownership stakes in all investments. We sum the total dollars invested in each industry in the home country. We then sum the total dollars invested in that industry in the home country in which the stake held by the SWF is controlling (defined to be over 20\%). Our measure, Perceived Skill, is this proportion, irrespective of the total dollars invested in that sector. To avoid extreme values for industries in which the SWF has no investment, we use the mean proportion from all SWFs.

As a final note, we recognize that state ownership might lead SWF managers to pursue development objectives poorly or to pursue other political or personal objectives or to face additional constraints in trying to realize their objectives. For now we focus solely on the planning aspect of development objectives to see what power this has in explaining allocation, and leave questions of ability to realize returns to this objective for future work.

\section{Methodology}

\section{III.1 Portfolio Choice Methodology}

Our empirical model most closely follows the portfolio choice specification of Massa and Siminov (2006), who focus on explaining investors' portfolio choices with the tension between hedging non-financial income risk and investing to familiar or informed sectors. The dependent variable in our portfolio choice model is the portfolio weight $w_{b f t}$ in asset class-industry-geography bin $b$ for SWF $f$ at time $t$ : 


$$
w_{b f t}=x_{b f t}^{\prime} \beta+d_{b f t}^{\prime} \alpha+\varepsilon_{b f t} .
$$

Included are two sets of independent variables. The $x_{b f t}$ 's are the financial portfolio benchmarks and the variables reflecting any allocation adjustments the SWF manager, acting as a pure asset manager, makes to hedge non-financial income risk or to reflect risk adjustments due to the wealth or fixed income positions of the country. The benchmarks themselves consist of four variables. Following the concepts in Dimmock (2010), we include both the mean allocation to the asset class provided by the capitalization and pension fund benchmarks to benchmark asset class strategies as well as the overall benchmark portfolio weights to capture within-asset-class industry and geography allocations. The pension fund allocations are home biased specifically for each SWF. The $d_{b f t}$ 's are the development benchmark variables, Strategic Plan, Perceived Market Failure, and Perceived Skill.

In testing this model we use a panel dataset with 20 SWFs and an average of 6 years per SWF. The error terms in (1) are undoubtedly serially correlated for a SWF. In the context of just looking for the portfolio tilt, we could simply cluster the estimation by SWF to resolve the issue of repeat observations, which happen to be serially correlated, since SWF heterogeneity left in the errors should be uncorrelated with the benchmark portfolios (following Bertrand, Duflo and Mullainathan (2004)). However, the inclusion of the non-financial income risk adjustment variables and the developmental variables leaves open the possibility for inconsistent estimates. Thus, following the design in Massa and Siminov (2006), we also implement a GLS model with an AR1 component:

$$
w_{b f t}=x_{b f t}^{\prime} \beta+d_{b f t}^{\prime} \alpha+\rho w_{b f, t-1}+\varepsilon_{b f t} .
$$

Because of the shortness of our panel, we use the two-step (Prais-Winsten) method in which the serial correlation parameter is first estimated from residuals and then inserted in the equation. 
Using these empirical approaches our results are estimated both (sequentially) in the panel and in the time series. Thus, although we are limited as to the number of SWFs studied, our AR1 results come from the changes in SWF positions.

We recognize that technically a cleaner implementation would also involve a portfolio adding-up condition via a constrained system (e.g., McGuire and Weiss (1976) applied to portfolios as in Dimmock (2010)). Because of the limited number of SWFs, particularly in the clustered standard errors model that we use for our main specification, we do not have sufficient observations to implement this model. What we can do is to follow the approach of Beckwith (1972) by examining robustness of our findings to a model in which one bin (real estate) is left out, such that the residual can force the adding-up.

\section{III.2. Ownership Stakes Methodology}

A parallel test to see whether portfolio investor or developmental objectives drive SWF choices is to look at the size of ownership stakes and if they differ across industries and geographies.

If SWFs act solely as simple portfolio investors, then diversification requires a larger number of small stakes, rather than concentrated positions. This view also has no specific predictions that ownership concentration will be greater in one particular industry or geography. In contrast, the developmental objective requires concentrated positions in specific industries. Concentration is required as state owners need to have control rights in firms to address coordination or information failures.

In Table 3 we report the percentage of the value of SWF investments where the SWF is potentially engaged in "active ownership" and therefore is not diversified. For this table the definition of active ownership we use is that the SWF has 5 percent or more of shares outstanding. The most striking statistic from the table is provided in column 4 where we report that $41 \%$ of the value of SWF public equity investments is active, by our definition. Panel A shows that SWFs are active in 5 of the 6 world regions (the exception being Latin America), with moderate level of active involvement in public equities in Europe and North America where slightly more than one eighth of the value of public equities are held 
actively. In Asia and the Middle East, close to 80 percent of equity value is held actively. These ratios based on public equities are an understatement of the percentage of their portfolios held actively, as SWFs have extensive private equity and real estate portfolios and almost all of these are active by our definition, in many cases with 100 percent ownership. Panel B is also interesting as it shows that the patterns of active positions are not similar across all industries but rather are focused on some industries. In particular, active positions exceed the mean in finance, transportation, transportation manufacturing and telecommunications, whereas they are less than 10 percent of the value of investment in consumer goods, consumer services, fabricated products and healthcare.

\section{Results}

\section{IV.1 Univariate Tests against Financial Investor Benchmarks}

Our first results are largely descriptive, providing new facts about SWF investments and providing a preliminary indication why it may be important to consider factors beyond risk-adjusted financial returns to explain SWF portfolios. Table 4 panels A and B presents the risky portfolio weights of SWFs and the two financial investor benchmarks, and shows these weights by geographic region. The SWF weights are an equal weighted average across the 20 SWFs of a time-series average within the SWFs. ${ }^{22}$ In Table 5 we repeat the analysis looking at the Industry breakdown. The summary statistics of Tables 4 and 5 show that SWF risky portfolios are focused to a much greater extent than pension plans on private equities and real estate, are much more focused on home countries, and have distinct industry tilts.

We begin by observing that the combined private equities and real estate holdings account for almost half the portfolio (48\%). The extent of the investments in non-public equities makes them quite distinct from our large institutional investor benchmark provided by defined benefit pension plans in Table 4 panel B (on the right hand side). These large institutional investors have less than one third the

\footnotetext{
${ }^{22}$ Because our analysis is in portfolio weights, all statistics are equally weighted, not value weighted.
} 
allocation in these non-public asset classes, with only 5.4 percent in private equities and 10 percent in real estate and other real assets.

SWFs also have a specific geography tilt. Compared to the large pension plans benchmark, SWFs invest 19.5 percent more of their overall portfolio in Asia and 35.9 percent more in the Middle East, underweighting North America. The greatest differences are in private equities in these markets, with a three time greater percentage allocation in private equities in Asia (11.7 percent of pension private equity in Asia relative to 31.4 percent for SWFs) and 49 percent of private equity in the Middle East whereas this is less than 12 percent for pension plans. SWFs invest almost all of their European, North American and Pacific investments through public equity. ${ }^{23}$

There are also distinct industry tilts. Table 5 repeats the cross-tabulation exercise for industries. In their financial portfolios SWFs overweight transportation, energy, real estate and finance compared with pension plan allocations. In the transportation industry the excess allocation by SWFs relative to pension plans is 7.1 percentage points ( $473 \%$ larger allocation than the mean pension plan,) in energy it is 6.4 percentage points ( $188 \%$ larger than the mean pension plan), in real estate the excess allocation is 8.7 percentage points ( $85 \%$ larger than the mean allocation to real estate by pension plans), and in finance it is 1.1 percentage points (6\% larger than mean allocation). The results for energy and transportation are particularly surprising given that the countries that are home to SWFs are often heavily weighted in these industries in their domestic production and are the polar opposite of what would be predicted assuming investors seek to hedge such income risk through their financial portfolios. ${ }^{24}$

Using world market capitalization as an alternative benchmark provides similar indications that SWF portfolio industry and geographic allocations are not easily captured by such financial portfolio investor measures. The capitalization benchmarks in Table 4 show the importance of North American

\footnotetext{
${ }^{23}$ The public equities allocation we report is an overstatement of investments where SWF have potential control rights, for it includes large indexed positions by SWFs like ADIA and GIC Singapore, as well as the quasi-indexed investments of Norway and Alaska. Norway invests relatively small stakes in a large number of companies (7,900 in 2008) and only has stakes in excess of 5 percent in 3 companies.

${ }^{24}$ Singapore, Malaysia, Norway and the Gulf States have large shipping and air transportation sectors.
} 
and Europe for public equities, collectively accounting for $71 \%$ of world capitalization with North America being the more important player. In private equities, the capitalization measure still finds these two regions dominate, collectively accounting for $56 \%$ of world private equity capitalization, with Europe's larger private markets making it the dominant player and other regions also play a larger role. Again, SWF allocations are tilted much more towards Asia and the Middle East respectively, particularly in private equities. The capitalization benchmarks in Table 5 also continue to show excess capitalization in industries of transportation, energy, real estate and finance, with finance, with indications also of excess capitalization in telecommunications and utilities as well.

\section{IV.2. Portfolio Choice Results}

To test for the importance of alternative objectives we turn to a regression framework. Table 6 reports our first set of estimations where we just use financial investor variables to predict the SWF portfolio weights (which sum to 100) across bins. In these tests we have an unbalanced panel with an average of 6 years of data per SWF. To capture asset class selection, we include as benchmark variables the mean allocation to the asset class provided by the capitalization and pension fund benchmarks (Capitalization: Mean Asset Class, Pension Fund: Mean Asset Class). To capture the within asset class industry and geography benchmarking, we include the overall benchmark portfolio weights, which sum to 1 across bins for the capitalization benchmark (Capitalization: Bin) and pension fund benchmark

(Pension Fund: Bin). The pension fund allocations are home biased specifically for each SWF.

In these tests we are interested in the results for the benchmark and hedging variables, but more importantly we are interested in their overall explanatory power captured in the r-squared for the different empirical models. In column 1, the financial portfolio investor benchmark variables produce an r-squared of 7.2 percent. Some of the power comes from the ability of the statistically significant capitalization benchmark to explain choices across asset class, but within the asset class what is most important is the pension benchmark. 
In column 2 we include the hedging variables to capture the potential impact of nonfinancial income. The inclusion of these variables has no impact on overall explained variation that remains at 7.2 percent, although some of the variables have some explanatory power. The positive and significant coefficient on the proportion of wealth in fixed income interacted with beta shows that SWFs from countries with significant fixed income wealth take on more beta risk in their risky portfolios. The negative and significant coefficient on the standard deviation of fiscal revenues interacted with beta shows that SWFs from countries where the fiscal revenue is more volatile take on less beta risk. Nothing else is significant, suggesting at least for the moment that hedging through industry choices is not a powerful component of SWF decisions. Column 3 repeats the exercise of column 2 using the GLS - AR1. The AR component is high, as one might expect. But importantly this does not change any of the main results.

In columns 4 through 6 we repeat the analysis on subsamples of the data to see if the results are similar across asset classes and as a test of their robustness. Column 4 reports the results where we ignore all real estate asset class investments and just focus on public and private equities (reweighting so that the allocations sum to 100). This imposes a Beckwith (1972) method of handling the adding up constraint. The results do not materially differ. In Column 5 and 6 we look at public equities and private equities respectively. Because we are just looking at a specific asset class we drop the asset class benchmarks from capitalization and pension plans for these models (re-weighting to sum to 100 again). When looking at public equities, we also drop one of the benchmarks, as within public equities these are highly correlated and would otherwise produce problems of multi-collinearity.

The positive and significant coefficient on the benchmark in column 5 shows the power of financial investor objectives. Consistent with other studies, we find no significance for the hedging variables. Column 6 shows results for just private equity. The industry-geography allocations in the benchmark fail to explain the portfolio allocations at all, as do all the hedging variables. 
We finalize this analysis by performing one additional test of the power of financial investor variables to explain public equities portfolios. For this test, we include two additional hedging variables that capture the possibility that SWF managers view their private equity portfolios as fixed and not tradable. For example, suppose part of the SWF initial endowment is a stake in a state-owned enterprise that can never be sold. Rather than seeing this as part of the financial portfolio, it might be better seen as part of their non-financial income.

In this case, the private equity industry and geography location provide exposure that ideally should be hedged through the public equity portfolio, and hedging should be more likely the larger the fraction of the portfolio not in public equities. To capture these possibilities we construct a variable $P E$ Weight, that is the overall private equity weight in the portfolio for that industry-geography bin, and the variable Non-public Weight that is the sum of real estate and private equity. Counter to the prediction that SWFs will use their public equity investments to hedge risk arising from existing and less liquid positions in industries arising from their private equity investments, we find that private equity investments predict public equity investments in the same industries and geographies and that the larger the size of their nonpublic equity investments, the greater the weight on more risky industries-geographies.

Table 7 repeats the analysis of Table 6, including developmental objective variables, Strategic Plan, Perceived Market Failure, and Perceived Skill. As column 1 shows, we include two Perceived Market Failure and three Perceived Skill variables. Because we are agnostic whether managers might employ their perceived skill or information advantage in investing at home, in the local region, or in the rest of the world, we interact Perceived Skill with these three geographies. For Perceived Market Failure, SWFs might have the incentive to overcome market failure either domestically or regionally where spillover benefits from investment might be most easily captured (imagine benefits to Singapore if investments in Malaysia pay off). For Strategic Plan, almost all of the planning is done with respect to the home market only. 
Column 1 reports that state planning variables also have power to explain patterns in industry choices, producing an r-squared of 5.7 percent. Higher allocation weights follow the existence of a Strategic Plan in an industry or Perceived Skill, but only in the domestic industry. That we find any result is particularly impressive as the planner variables should have no power for SWFs in countries without strategic plans ${ }^{25}$ or those that do not rely upon natural resource wealth to fund the SWFs. Perceived Market Failure is positive but not significant. In column 2 we repeat column 2 of Table 6 to facilitate a discussion of how the hedging picture changes once we add the state planning variables.

Column 3 presents our third main finding of the paper. When including both the financial portfolio investor and state planning objectives, the R-Square increases to 14.3 , consistent with the two sets of objectives picking up different dimensions to SWF choices. Comparison of r-squared with columns 1 and 2 reveal that the partial r-square of state industrial planner variables is 7.1 and that of the financial variables is 8.6. State planner variables thus account for 45 percent of the explained variation. ${ }^{26}$

Two important changes appear in column 3 with respect to columns 1 and 2. First, once controlling for the financial planner covariates, we see that Perceived Market Failure is now positive and significant, not just domestically, but also regionally. Second, in what we think is an important reversal from the results when we just considered financial objectives, the sign on the hedging variable shifts from positive to negative and becomes significant. Once we control for the tilt in portfolio coming from industrial planning objectives, SWFs do tilt away from their non-financial risk. Thus, although our initial findings support the negative hedging results of Massa and Siminov (2006), it seems that asset managers may take the lessons of financial literature and hedge risk, once they have followed what might be considered mandates for development.

What are the economic magnitudes of hedging and state industrial planning measures? To put the figures in perspective, with 189 bins, a completely equal, naïve weighting across all bins would lead to

\footnotetext{
${ }^{25}$ Kuwait, Norway Domestic, Kazakhstan Domestic, Alaska

${ }^{26}$ Much of the residual results from our inability to capture the geography of the holdings, and our unwillingness to include ad hoc variables, e.g., a domestic dummy. If we collapse to an industry-level analysis, our r-square increases to 22 percent.
} 
0.529 percent weight in each bin. First, we look at the hedging variables. A one standard deviation increase $(0.013)$ in the covariance variable induces 0.05 percent less allocation in the bin $(9.5 \%$ less than the naïve weight). This magnitude, although small, is not trivial relative to the naïve weight. Likewise, for fixed industry betas, countries with one standard deviation larger fixed income of the country relative to SWF assets (2.04, a huge number given some of the large foreign reserves in our sample), results in 0.038 percent more allocation to the bin $(7.2 \%$ more than the naïve weight $){ }^{27}$

For state industrial planning, a one standard deviation (0.343) larger Perceived Skill in an industry induces SWF managers to invest 1.26 percent more in home country (a $227 \%$ increase from the naïve weight). Likewise, the existence of an industrial plan induces SWF managers in invest 0.717 more of their portfolio in that home industry ( $136 \%$ increase from the naïve weight). On average, SWFs have 3.2 such industries. A one standard deviation larger Business Opportunity Public Good score (0.087) associates with SWFs investing 0.38 percent more in the domestic and 0.24 percent more in the regional bins (a $72 \%$ and $45 \%$ increase respectively). These are very large magnitude effects. But, as we saw in the initial summary statistics tables, the biases we are trying to explain are also large. In column 4 we repeat the analysis excluding the state planning variable, producing very similar quantitative and qualitative results on the other state industrial planning variables. And in column 5 we repeat the analysis of column 3 with the GLS- AR1 specification, again producing very similar results.

In the final three columns we first focus just on equities (private and public) by excluding real estate, then we look within the allocations of first public equity and then private equity. The pension benchmark is large in magnitude and significant for public equities and insignificant for private equities. The coefficient on covariance hedging remains large in both columns and significant in the public equities column. The industrial planning variables show up strongly in private equity and in public equity. In fact, because of the importance of industrial plan for private equity allocations, the R-Square is higher in the

\footnotetext{
${ }^{27}$ In an earlier version of the paper, we show that the importance of planning variables also depends upon country characteristics, including the starting level of diversification across industries, and the perceived need for planning (e.g. the number of years until the natural resource that serves as the basis for the SWF funding and national wealth runs out). To simplify the exposition, we have excluded the variables in this presentation.
} 
private equity specifications (0.149) than the public equity ones $(0.105)$, even though the financial portfolio variables do poorly in explaining private equity allocations.

Also interesting in column 7 is the positive significance of Perceived Skill in the foreign market. This is at least consistent, if not suggestive of, SWFs who want to invest outside their local region with control doing so in private equity markets to avoid public scrutiny. We return to this point when we look at ownership in the next section.

One final noteworthy point emerges from the public equity column in Table 7 (column 7). In the parallel specification from Table 6 without the inclusion of the state planning variables, the private equity "endowment" hedging variable and the alternatives risk-preference hedging variable were both of the wrong sign and significant. SWFs seems to tilt toward public equity industries in which they have large private equity stakes and toward more risky public equity industries, the more alternatives they have in their portfolios. Both of these results, which are counterintuitive, can be explained by state planning; they become insignificant in Table 6.

\section{IV.3 Heterogeneity Analysis in Portfolio Choice Results}

In this section, we explore how financial versus state planning objectives matter across the heterogeneity of SWFs. The two objectives might capture different dimensions to the same fund and/or the heterogeneity in objectives by fund. To disentangle these possibilities we look separately at the explanatory power of these financial and state planning variables for each fund and decompose the rsquared based on the objective.

To explore heterogeneity, we begin by breaking down R-Square:

$$
R \text {-Square }=1-\frac{S S E}{S S T}=1-\frac{\sum\left(\omega-\hat{\omega}_{F I}-\hat{\omega}_{S P}\right)^{2}}{\sum(\omega-\bar{\omega})^{2}}
$$

$\omega, \hat{\omega}_{F I}, \hat{\omega}_{S P}$ and $\bar{\omega}$ respectively refer to (without fund, time and asset-class-industry-geography bin subscripts) the SWF portfolio allocation (the dependent variable), the predicted portfolio weight using just the financial investor variables, the predicted portfolio weight using just the state planning variables and 
the average allocation (which equals 1 divided by the number of bins). The summation is over all observations in a general setting, but we are going to do this summation over all observations for each

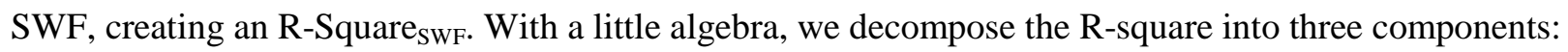

$$
R \text {-Square }_{S W F}=R-\text { Square }_{F I, S W F}+R-\text { Square }_{S P, S W F}-\left(1-\frac{\sum 2 \hat{\omega}_{F I} \hat{\omega}_{S P}}{\sum(\omega-\bar{\omega})^{2}}\right)_{S W F} .
$$

In short, an R-Square for each of the set of objective variables and then a "covariance R-Square", the part of the explained sum of square errors which both variables explain.

Figure 1 presents the results of this decomposition for column 3, Table 7 results. As we noted in the prior section, the financial investor and industrial planner model explains 14.4 percent of the variation in risky portfolio holdings across industries, geographies and three asset classes. This does not mean that the model does equivalently well across SWFs. In Figure 1, the first bar (the medium grey/blue one) presents the R-Square ${ }_{S W F}$, with the SWFs ordered on this variable. The model fits the portfolios best for the Kazakh Global Fund (a pure indexer). Some other portfolios are explained extremely well by the model, including SWFs one might guess - GIC Singapore, Alaska, and Norway - and including ones one might not expect - Bahrain, Qatar, and two Dubai funds.

The remaining two bars in Figure 1 show that the SWFs explained very well by the model (over 25 percent of the variation explained) are primarily financial investors with the notable exceptions of Bahrain and the Investment Corporation of Dubai. Of the SWFs explained still reasonably well (with 15 to 25 percent of the variation explained), half are state planning (development SWFs); namely Kuwait, Temasek and Malaysia. The SWFs to the extreme right in Figure 1 are not captured well by the model, but to the extent that the model has some power, it is usually in the state planning variables.

\section{IV.4 Ownership Stake Results}

The data we have constructed on individual positions provides the opportunity for a different test of the importance of financial portfolio and developmental objectives in SWF investments. As we noted in the introduction, if SWFs act solely as simple portfolio investors, then diversification requires a large 
number of small stakes, rather than concentrated positions, and there are no specific predictions that ownership concentration will be greater in one particular industry or geography. In contrast, the developmental objective requires concentrated positions in specific industries. Concentration is required as state owners need to have control rights in firms to address coordination or information failures.

To explore these predictions, in Table 8 we use as a dependent variable the ownership concentration in SWF investments for a geography-asset class- industry bin where a bin has a positive stake and as explanatory variables measures of developmental objectives, as only these variables generate specific predictions. ${ }^{28}$. Because we do not observe the ownership stakes in the indexed portions of a few SWF portfolios (tabulated in Table 1), we assume that stakes held in index funds have the average ownership holding of the Norwegian Global Fund (0.00075 ownership stake), a very diversified, nonactive manager. As in the prior tables, the first three columns are estimated with OLS with clustered standard errors at the SWF level. Columns 4-6 are estimated with GLS-AR1.

We are interested in two independent variables. First is the overall SWF R-square as pictured in Figure 1 and explained in the heterogeneity section. Figure one suggests that those SWFs who are explained best by the model are those whose portfolios look like financial investors. If so, a negative relationship between the SWF R-square and ownership stakes would be consistent with asset managers acting as passive, diversified investors seeking portfolio income.

The second independent variable is the fraction of r-square identified by the state planner variables over r-square of the financial plus state planner, or $\frac{R_{S P, S W F}^{2}}{R_{S P, S W F}^{2}+R_{F I, S W F}^{2}}$. Our hypothesis, supporting the evidence in the summary statistics sections from earlier, is that the more a SWF wants to enact industrial or developmental goals, the larger the ownership stakes should be. The columns going across always have a dummy for asset class (private equity and real estate always have higher ownership

\footnotetext{
${ }^{28}$ If we allow non-positive holding bins, then we might well be identifying estimates off having a holding or not, not off ownership stakes conditional on holdings.
} 
stakes), and we add region and industry fixed effects to ensure the results are not an industry or geography omitted variable.

We find that the SWF heterogeneity in objectives and model fit does offer explanatory power for ownership stakes. The second variable is of primary interest. In our most stringent specifications (columns 3 and 6), the coefficient on the fraction explained by state industrial planning is in the range from 0.0041 to 0.0058 and significant. The standard deviation on this variable is high (1.3), since the explanatory power of the model seems often to load on one objective or another. If the fraction explained by developmental objectives increase by one standard deviation, the coefficients imply the ownership stake would increase by $0.0056-0.0079$. The mean stakeholding, conditional on non-zero holdings, is 0.0561 .

\section{IV.5. Discussion}

Recognizing the role of developmental objectives in portfolios has broader implications for the effects of SWFs on global capital markets. To the extent that these objectives are permanent characteristics this implies a continued tilt in investments to specific industries and geographies. If other investors do not perfectly respond to these inflows by reducing their demand, this will lead to price and resource allocation impacts. Also, the political importance of these investments suggests a potential lexicographic ordering of importance of investments - first to those investments associated with industrial plans and then to those not associated with plans. This would imply that SWFs may respond differently to external shocks than financial investors with a long time horizon, using those non-plan investments to cushion the impact of shocks. This is counter to the prediction that SWFs would increase investments to respond to shortterm mispricing as they would if they were solely long horizon financial investors and offers one explanation for the relative lack of SWF investment in the midst of the financial crisis. It also suggests dramatically scaled back expectations for the resources available from SWFs to engage in long horizon investing. 
Our results suggest that for the new institutional investor class of SWFs sovereignty does matter as it influences portfolio choices and approaches to management. This developmental agenda is not altogether surprising. As Rajan (2010) has recently emphasized, successful development in emerging markets has not been based solely on free markets dictating the allocation of resources, but has relied upon a heavier hand of the state in directing economic activity. Showing how this form of developmental politics influences choices does not mean other objectives are not at play, but it leaves much less to be explained.

One interesting aspect about this form of state capitalism is that the government is spurring investments in specific industries not through more conventional means such as debt finance or state ownership. Relative to these mechanisms, investment through (often minority) equity stakes has some significant disadvantages. The state cannot as easily direct economic activity or the transfer of information to fulfill market failures, if that is its intention. The lack of transparency of this mechanism seems to open the room for non-efficiency based political allocations. If this approach produces inefficiency, there is also a significant opportunity cost. Against these concerns are potential advantages in achieving political goals, as with equity investments the state has the potential to redirect more resources. First there are the resources of other equity investors, and then there is leveraging if the invested firms borrow in private markets to support this activity as we saw in Dubai. Whether the advantages outweigh the disadvantages and this is a sustainable proposition remains an open question.

\section{Conclusion}

In this paper we have assembled a novel data set of SWF portfolio holdings. We analyze their portfolios, and try to understand the investment objectives driving those portfolio decisions. We distinguish two broad objectives: portfolio investment vs. developmental objectives. We then introduce measures to capture these objectives and examine their power to explain portfolio allocations and ownership stakes. 
One view is that SWF investments are motivated solely by securing appropriately risk-adjusted financial returns, predicting broad industry and geographic diversification in their portfolios, as well as across alternative types of risky assets. This portfolio investor view has power to explain portions of their portfolio allocations, but leaves much to be explained.

We find that considering the possibility that portions of their portfolios are driven by a desire to achieve developmental objectives provides significant additional explanatory power. This objective predicts more domestic and regional investments, and more focused allocations consistent with announced planning objectives, and we also see this in the data. Considering both objectives also helps us to understand better the heterogeneity across funds, with some driven solely by portfolio investor objectives, others by planning objectives, and many apparently addressing both. Developmental objectives are important for all of the large Middle Eastern and some of the Asian SWFS.

Showing that funds pursue industrial planning objectives does not mean that they necessarily do this well, or that this is the best mechanism to achieve these objectives. The attempt to achieve planning objectives by taking equity stakes in private companies also raises questions whether this is the best mechanism to achieve these objectives, and how sustainable is this approach. There are alternatives, including direct state subsidies delivered either through state owned enterprises or through direct subsidies to private firms. This could very well be done poorly, or a mechanism that provides some political cover for other activities. Looking solely at portfolios cannot address these questions, but we need to turn to returns, a topic we pick up in ongoing work. 


\section{Appendix A - What is a SWF?}

We employ a commonly used definition provided by the Monitor group, which defines SWF to be: (a) wholly owned by a sovereign government, but organized separately from the central bank or finance ministry; (b) an investment fund rather than an operating company; (c) an investor that makes international and domestic investments in variety of risky assets, (d) and is charged with seeking a commercial return; and (e) a wealth fund rather than a pension fund - not financed with contributions from pensioners and does not have a stream of liabilities committed to individual citizens and state-owned enterprises.

\section{$\underline{\text { Appendix B - SWF Portfolio Data Collection }}$}

The strategy to re-construct hidden portfolios has three steps. First we identify all of the subsidiaries acting as the investing entities. SWFs usually only partially disclose their organizational structure delineating the names of the investing entities underneath the SWF. We cross-reference our entity list with subsidiaries listed in Bloomberg, Capital IQ, Zawya, Thomson, and the SWF Institute. To ascertain that we capture the all SWF entities which are making investments of any magnitude for the parent SWF, we work backwards from the known portfolio companies owned by the SWF. Knowing these companies allows us to search Factiva news articles and SDC transaction data to identify the exact entity doing the investing. Our overlap is high across these methods, but each step added more entities and allowed us to understand the relationships among entities.

Second, we search for transactions and ownership data involving these entities through a host of possible sources - including entity websites, Amadeus, Bloomberg, Capital IQ, Compact D, Datastream, Dealscan, Dow Jones Zawya, Edgar/SEC, Galante's Alternative Investment Sources, SDC/Thomson One Banker, and Venture Xpert. These sources do not capture all of the investments and usually do not give us the value of the holdings unless the transaction is a high-profile event. However, the union of transactions and holdings captured in these data sources provide a starting point for performing case studies of each transaction. By this we mean that for each company the SWF supposedly invests in, we search extensively in world news sources (via Factiva and Google in multiple languages sometimes) to ensure that we have multiple records of the initial transaction or certification that the holding exists, that we reconcile any increases in stake or divestments with additional transactions, and that we can put a stake on each holding. In the process, we get a very detailed picture of the SWF's operations and are often led to additional investments made by the funds either from articles on known transactions or via broad sweep searches.

Third, we value the holdings dynamically. The valuation of each company at each point in time is particularly tricky. For publicly traded companies, this is a straightforward task, and a dynamic picture of equity stakes is sufficient. However the private equity and real estate holdings require some assumptions. In particular, the best that we can often do is the equity stake (usually), an initial transaction value (sometimes) and yearly revenue or net income numbers (often) for the company to which we apply an industry-region multiple. When we only observe revenue numbers for some points in time, we have to infer growth with the industry. We mark these for incorporating this forcing in the analysis. If we are missing financials altogether, we use output measures (e.g., dry weight tons for shipping and passengers for airlines), which we try to capture yearly. Although our valuations are far from perfect, we think that our errors will not create biases in the residual portfolio and note that our errors are likely to be the greatest for the smaller companies in the portfolios who are less likely to issues newswires on performance or publish financials.

The next step is to value each of the assets dynamically for the three asset classes. For publicly traded companies, this is a straightforward task; we simply download stock trading data from Thomson and Bloomberg and apply the prices or market capitalizations to the dynamic picture of shares held or equity stakes. 
For direct private equity holdings, we have a few different levels of data availability and thus approaches. If we know the investment and divestment amount (or a valuation at an IPO), we calculate the gross return and allocate this return over time scaled to be proportional to the three-digit SIC code return for the region. ${ }^{29}$ If we observe the investment, the percentage held, and either a revenue, income or asset figure, we calculate a firm-specific multiple at the point of investment to allow the investment to grow with the firm. If we observe only the percentage held and a revenue, income or asset figure, we apply the three-digit industry multiple specific to region and year. Within these last two scenarios, when we lack the financials data, we capture yearly output measures (e.g., dry weight tons for shipping and passengers for airlines) and apply up publicly traded comparables output-to-value multiples. Finally, in the few cases in which we only know the investment amount and nothing else, we apply industry growth for the region.

The third asset class needing valuations are properties. As in private equity, if we know the transacted prices of buying and selling a completed structure, we calculate the gross return and allocate this return over time scaled to the real estate return for the regional area. If we know the purchase price only, we grow the transacted price with the regional area return for the years held. If we know when a property was purchased but not the price, we use heuristics valuation based on property size, location and type, assuming that all properties are class A commercial, residential, retail, or lodging. After looking up the sizes in Factiva, Google or Zawya, we convert all size measures (e.g., apartment units, retail spaces, hotel rooms) to square footage and use the Collier data for region price per square foot for the transacted year as the purchase price. We then grow this value with the region area growth rate.

\footnotetext{
${ }^{29}$ The return for year $t$ is $\exp (\ln (X /$ YearsHeld $) * I n d u s t r y R e t u r n$, where $X$ is the investment gross return (divestment divided by the investment) scaled by the region industry return over the period. The regions are defined as Asia, Europe, Latin America, Middle East \& Africa, North America, Pacific and home country. To calculate the region returns and the region multiples, we use all firms in the Thomson OneBanker database, which includes Worldscope and Datastream data.
} 


\section{References}

Ang, Andrew, 2010, "The Four Benchmarks of Sovereign Wealth Funds", Columbia Business School Working Paper.

Bauer, Rob and Rik Frehen, 2008, “The Performance of US Pension Funds: New Insights into the Agency Cost Debate," SSRN Working Paper.

Beckwith, Neil E., "Regression Estimation of the Time Varying Effectiveness of Advertising," unpublished paper, 1972.

Bertrand, Marianne, Duflo, Esther, Mullainathan, Sendhil, 2004. "How Much Should We Trust Differences-in-Differences Estimates?," The Quarterly Journal of Economics, MIT Press, vol. 119(1), pages $249-275$

Bitler, Marianne P., Moskowitz, Tobias J., Vissing-Jørgensen, Annette, "Testing Agency Theory with Entrepreneur Effort and Wealth." Journal of Finance, 2005, 60(Issue 2), pp. 539

Bodie, D., R. Merton and W. Samuelson, 1992, "Labor supply flexibility and portfolio choice in a life cycle model, “ Journal of Economic Dynamics and Control, 16, 427-449

Conway, Nicoletti, 2006. "Product Market Regulation in the Non-Manufacturing Sectors of OECD Countries: Measurement and Highlights," OECD Economics Department Working Papers 530, OECD Publishing

Dimmock, S. 2009, "Background Risk and University Endowment Funds," working paper, Michigan State University.

Dyck, Alexander and Adair Morse (2011b) "Asset Management, Sovereign Incentives and Governance: Return Implications for Citizens".

Dyck, Alexander and Lukasz Pomorski , 2010, "Is Bigger Better? Size and Performance in Pension Plan Management” Social Science Research Network Working Paper Series

French, Kenneth, 2008. "Presidential Address: The Cost of Active Investing," Journal of Finance, American Finance Association, vol. 63(4), pages 1537-1573

General Accounting Office. 2008. "Sovereign Wealth Funds: Publicly Available Data on Sizes and Investments for Some Funds Are Limited," GAO 08946. 
Guiso, Luigi, Jappelli, Tullio, Terlizzese, Daniele, 1996. "Income Risk, Borrowing Constraints, and Portfolio Choice," American Economic Review, American Economic Association, vol. 86(1), pages 15872

Hall, Robert, Woodward, Susan E., 2007. The Incentives to Start New Companies: Evidence from Venture Capital," NBER Working Papers 13056, National Bureau of Economic Research, Inc.

Heaton, John, Lucas, Deborah, 2000. "Portfolio Choice and Asset Prices: The Importance of Entrepreneurial Risk," Journal of Finance, American Finance Association, vol. 55(3), pages 1163-1198

Massa, Massimo and Andrei Simonov. 2006. "Hedging, Familiarity and Portfolio Choice"; Review of Financial Studies

McGuire, T.W., Weiss, D.L., Logically Consistent Market Share Models II. J. Marketing Research, 13 (1976), 296-302

Merton, R., 1992, “Optimal Investment Strategies for University Endowment Funds," in R. Merton (ed.) Continuous Time Finance - Revised Edition, Blackwell: Malden, MA.

Moskowitz, Tobias, Annette Vissing-Jorgensen The Returns to Entrepreneurial Investment: A Private Equity Premium Puzzle? , 2002, American Economic Review, Vol. 92 No. 4, 745-778

Prudential Real Estate Investors, 2010

Rajan, Raghuram, 2010, Fault Lines: How Hidden Fractures Still Fracture the World Economy, Princeton University Press: Princeton, NJ

Santiso, J, 2009. "Sovereign Development Funds: Financial Actors in the Shifting Wealth of Nations," Chapter 16, New Perspectives on Sovereign Asset Management, editor Malan Rietveld

Truman, Edwin M., 2007, "Sovereign Wealth Funds: The Need for Greater Transparency and Accountability", Peterson Institute Policy Brief No. PB07-6. August.

Truman, Edwin M. 2008a. "A Blueprint for Sovereign Wealth Fund Best Practices," Peterson Institute for International Economics, Policy Brief 8-3.

Vissing-Jorgensen, Annette 2002. "Limited Asset Market Participation and the Elasticity of Intertemporal Substitution," Journal of Political Economy, University of Chicago Press, vol. 110(4), pages 825-853 
Figure 1: Heterogeneity in Proportions Explained and Objectives

The proportions plotted result from Column 3 estimates from Table 7. As described in the text, we

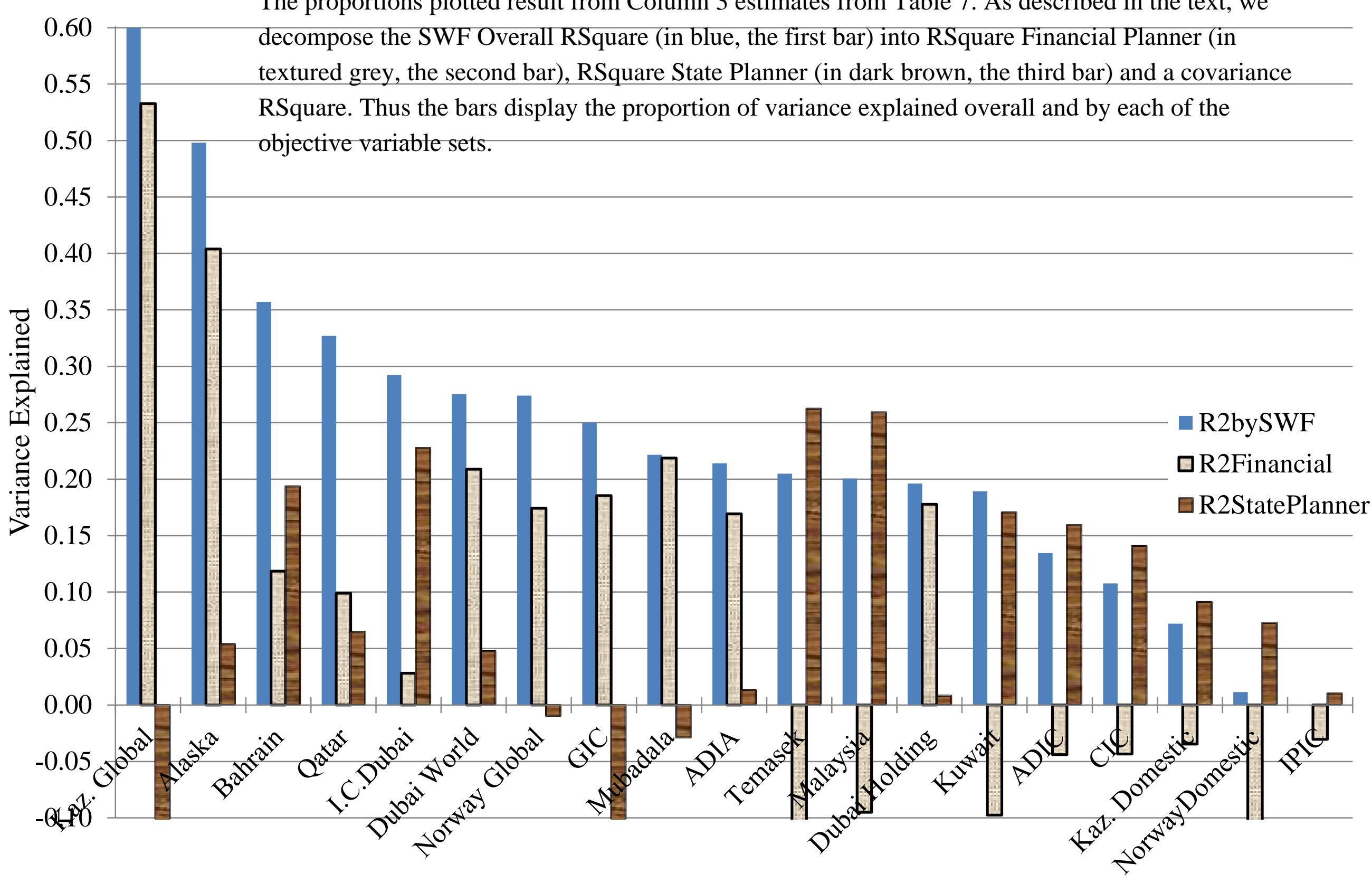




\section{Table 1 - Sovereign Wealth Funds Holdings for 2008: Our Data and Market Estimates}

Included SWFs meet the Monitor definition of a SWF and had at least \$10 billion in assets as of end of year 2007. Market estimates of SWF size come from Preqin and the Sovereign Wealth Fund Institute. The data presented here are for 2008, with our unbalanced panel starting in 1999. Column 3 and 4 are used in the analysis. Specifically identified means that we have the specific company or property information. Column 5 lists the number of companies over the sample period. This number is much smaller than the number of transactions. The number in parentheses excludes Alaska and Norway.

\begin{tabular}{|c|c|c|c|c|c|c|c|}
\hline & & & Of $\mathrm{t}$ & is Paper's & alculated Tot & tal: & \\
\hline & $\begin{array}{c}\text { Estimates } \\
\text { in Market } \\
1\end{array}$ & $\begin{array}{c}\text { This Paper's } \\
\text { Calculated } \\
\text { Total } \\
2\end{array}$ & $\begin{array}{c}\text { Risky } \\
\text { Portfolio } \\
\text { Specifically } \\
\text { Identified: } \\
\text { Equities \& } \\
\text { Real Estate } \\
3\end{array}$ & $\begin{array}{c}\text { Risky } \\
\text { Portfolio } \\
\text { Indexed } \\
4\end{array}$ & $\begin{array}{l}\text { Number of } \\
\text { Unique } \\
\text { P.E.Funds, } \\
\text { Properties } \\
\text { \& Firms } \\
5\end{array}$ & $\begin{array}{c}\text { Bottom-up } \\
\text { Inferred } \\
\text { Fixed } \\
\text { Income } \\
6\end{array}$ & $\begin{array}{l}\text { Bottom-up } \\
\text { Inferred } \\
\text { Hedge } \\
\text { Funds, } \\
\text { Other } \\
7\end{array}$ \\
\hline Abu Dhabi Investment Authority & 627,000 & 289,154 & 60,257 & 138,671 & 101 & 58,700 & 31,526 \\
\hline Abu Dhabi Investment Council & combined & 14,896 & 10,736 & & 33 & 2,377 & 1,783 \\
\hline Alaska & 26,700 & 28,756 & 17,696 & & 10,172 & 6,580 & 4,480 \\
\hline Bahrain - Mumtalakat & 14,000 & 19,321 & 19,321 & & 37 & 0 & 0 \\
\hline China Investment Corporation & 200,000 & 261,412 & 164,244 & & 16 & 97,168 & 0 \\
\hline Dubai Holding & 103,000 & 81,483 & 81,363 & & 191 & 0 & 120 \\
\hline Dubai World & 120,000 & 121,782 & 121,782 & & 153 & 0 & 0 \\
\hline GIC - Singapore & 220,000 & 235,250 & 54,538 & 67,168 & 333 & 79,200 & 34,344 \\
\hline Investment Corp. of Dubai & 82,000 & 74,056 & 73,409 & & 79 & 0 & 647 \\
\hline IPIC - Abu Dhabi & 16,000 & 18,601 & 16,804 & & 19 & 1,798 & 0 \\
\hline Kazakhstan National Fund & 22,700 & 22,072 & 0 & 4,139 & $\mathrm{n} / \mathrm{a}$ & 17,934 & 0 \\
\hline Kazyna-Samruk (Kazakhstan) & 52,000 & 46,209 & 46,209 & & 101 & 0 & 0 \\
\hline Khazanah Malaysia & 18,243 & 17,544 & 17,544 & & 92 & 0 & 0 \\
\hline Kuwait Investment Authority & 228,000 & 191,477 & 89,189 & 24,893 & 157 & 60,410 & 16,985 \\
\hline Libya Investment Authority & 65,000 & 76,040 & 15,303 & & 83 & 60,692 & 45 \\
\hline Mubadala (Abu Dhabi) & 13,300 & 28,262 & 28,012 & & 68 & 0 & 250 \\
\hline Norway Fund - Global & 323,505 & 316,228 & 153,267 & & 14,482 & 162,961 & 0 \\
\hline Norway Fund - Domestic & 12,342 & 12,342 & 6,541 & & 253 & 5,801 & 0 \\
\hline Qatar Investment Authority & 60,000 & 58,043 & 35,607 & 16,240 & 80 & 5,351 & 845 \\
\hline Temasek Singapore & 122,000 & 127,734 & 111,455 & & 309 & 14,072 & 2,207 \\
\hline Total Funds & $2,325,790$ & $2,040,662$ & $1,123,276$ & 251,111 & 26,759 & 573,044 & 93,232 \\
\hline Average Size & 116,290 & 102,033 & 56,371 & 56,371 & $1,408(124)$ & 28,652 & 4,662 \\
\hline
\end{tabular}




\section{Table 2: Summary Statistics}

See the text for definitions. All statistics excetp one are for the full sample of 23,247, which represents 2 asset classes (public and private equity) times 7 gerographies times 13 industries plus 1 asset class (real estate) times 7 geographies. The seven geographies are Asia, Europe, Latin America, Middle East \& Africa, North America, the Pacific and the home country. The industries are those in Table 4. Ownership stakes reported are those conditional on some ownership in the industry-asset classgeography bin. Ownership stakes are the equal weight average investment stake in that bin.

\begin{tabular}{lcccccc}
\hline & Mean & St.Deviation & Minimum & Median & Maximum Observations \\
\cline { 2 - 6 } SWF Risky Portfolio Weight & 0.0053 & 0.0312 & 0 & 0 & 0.872 & 23,247 \\
Ownership Stake | Stake>0 & 0.0561 & 0.1660 & 0 & 0.0008 & 1 & 11,874 \\
& & & & & & \\
Financial Portfolio Investor Variables & & & & & & \\
Pension Benchmark Weight & 0.0053 & 0.0141 & 0 & 0.0003 & 0.1519 & 23,247 \\
Capitalization Benchmark Weight & 0.0053 & 0.0129 & 0 & 0.0017 & 0.1911 & 23,247 \\
Financial (SWF) Wealth (\$ million) & 76,759 & 660 & 38,538 & 87,676 & 412,389 & 23,247 \\
Non-Financial (Fiscal) Wealth (\$ million) & 151,378 & 474 & 28,047 & 609,470 & $4,836,244$ & 23,247 \\
Percentage Non-Financial / Wealth & 0.4977 & 0.0154 & 0.5439 & 0.2676 & 0.9962 & 23,247 \\
Foreign Reserves Value (\$ million) & 71,689 & 1,594 & 31,694 & 219,570 & $1,949,260$ & 23,247 \\
St. Deviation Fiscal Revenues & 2.133 & 0.001 & 1.732 & 2.278 & 13.462 & 23,247 \\
Beta & 0.840 & -4.828 & 0.868 & 1.146 & 3.723 & 23,247 \\
Sign of Correlation (Bin, Fiscal Revenues) & 0.252 & -1 & 1 & 0.968 & 1 & 23,247 \\
Covariance (Bin Return, Fiscal Revenues) & 0.0007 & -0.2061 & -0.0004 & 0.0192 & 0.3465 & 23,247 \\
& & & & & & \\
State Planning Variables & & & & & & 23,247 \\
Strategic Plan & 0.1235 & 0 & 0 & 0.3291 & 1 & 23,247 \\
Perceived Market Failure & 0.1239 & 0.0357 & 0.0713 & 0.0870 & 0.4288 & \\
Perceived Skill & 0.2658 & 0 & 0.1072 & 0.3433 & 1 & 23,247 \\
\hline
\end{tabular}


Table 3: Sovereign Ownership of World Markets \& Active Investments: 2008 Snapshot

This table presents information on control rights associated with investments, classifying a stake as active if the SWF has 5\% or more of the shares of a firm. Panel A breaks down stakes by region, and panel B by industry, in both cases presenting data for public equities and private equities separately.

\begin{tabular}{|c|c|c|c|c|c|c|c|}
\hline & & Public & Equity & & & Private Equity & \\
\hline Panel A: by Region & $\begin{array}{c}\text { Market } \\
\text { Capitalization } \\
\text { (billions USD) } \\
1\end{array}$ & $\begin{array}{c}\text { SWF } \\
\text { Investments } \\
\text { (billions USD) } \\
2\end{array}$ & $\begin{array}{c}\text { \% World } \\
\text { Market } \\
\text { Capitalization } \\
\text { Held by SWFs } \\
3\end{array}$ & $\begin{array}{c}\text { \% of Value } \\
\text { Invested } \\
\text { Actively } \\
4\end{array}$ & $\begin{array}{c}\text { Private } \\
\text { Capitalization } \\
\text { (billions USD) } \\
5\end{array}$ & $\begin{array}{c}\text { SWF } \\
\text { Investments } \\
\text { (billions USD) } \\
6\end{array}$ & $\begin{array}{c}\text { \% World } \\
\text { Private Equities } \\
\text { Capitalization } \\
\text { Held by SWFs } \\
7\end{array}$ \\
\hline Asia & 5,842 & 250 & $4.3 \%$ & $79.3 \%$ & 12,412 & 135 & $1.1 \%$ \\
\hline Europe & 10,016 & 221 & $2.2 \%$ & $15.9 \%$ & 19,259 & 24 & $0.1 \%$ \\
\hline Latin America & 1,648 & 12 & $0.8 \%$ & $1.7 \%$ & 5,759 & 0 & $0.0 \%$ \\
\hline Middle East \& Africa & 763 & 49 & $6.4 \%$ & $80.8 \%$ & 1,364 & 164 & $12.0 \%$ \\
\hline North America & 12,714 & 154 & $1.2 \%$ & $14.1 \%$ & 10,044 & 8 & $0.1 \%$ \\
\hline Pacific & 4,304 & 45 & $1.0 \%$ & $8.3 \%$ & 10,837 & 11 & $0.1 \%$ \\
\hline Total & 37,447 & 731 & $2.0 \%$ & $40.8 \%$ & 59,675 & 342 & $0.6 \%$ \\
\hline Panel B: by Industry & 1 & 2 & 3 & 4 & 5 & 6 & 7 \\
\hline Consumer Goods & 1,959 & 24 & $1.2 \%$ & $6.0 \%$ & 2,135 & 6 & $0.3 \%$ \\
\hline Consumer Services & 4,527 & 69 & $1.5 \%$ & $9.3 \%$ & 33,500 & 28 & $0.1 \%$ \\
\hline Energy & 4,002 & 59 & $1.5 \%$ & $10.5 \%$ & 848 & 96 & $11.3 \%$ \\
\hline Fabricated Products & 895 & 11 & $1.3 \%$ & $4.4 \%$ & 2,229 & 0 & $0.0 \%$ \\
\hline Finance & 6,221 & 297 & $4.8 \%$ & $70.3 \%$ & 5,015 & 83 & $1.7 \%$ \\
\hline Food & 1,144 & 17 & $1.5 \%$ & $18.0 \%$ & 1,059 & 1 & $0.1 \%$ \\
\hline Healthcare & 2,874 & 35 & $1.2 \%$ & $4.7 \%$ & 582 & 3 & $0.5 \%$ \\
\hline Materials & 3,095 & 43 & $1.4 \%$ & $13.3 \%$ & 6,975 & 14 & $0.2 \%$ \\
\hline Technology & 1,943 & 23 & $1.2 \%$ & $11.3 \%$ & 1,440 & 0 & $0.0 \%$ \\
\hline Telecommunications & 3,598 & 66 & $1.8 \%$ & $45.2 \%$ & 756 & 3 & $0.4 \%$ \\
\hline Transportation & 928 & 27 & $2.9 \%$ & $65.5 \%$ & 2,354 & 18 & $0.7 \%$ \\
\hline Transportation Manufacturing & 1,230 & 21 & $1.7 \%$ & $33.3 \%$ & 1,261 & 41 & $3.2 \%$ \\
\hline Utilities & 2,359 & 38 & $1.6 \%$ & $19.3 \%$ & 977 & 19 & $1.9 \%$ \\
\hline Total (excluding real estate) & 34,773 & 731 & $2.1 \%$ & $40.8 \%$ & 59,130 & 311 & $0.5 \%$ \\
\hline
\end{tabular}


Table 4: Geography of SWF and Benchmark Portfolio Allocations

Table A presents the equally weighted SWF portfolio allocations, where each SWF is based on its time series average. Panel B reprots allocations based on world market capitalization and large pension funds. In panel B the median pension benchmark real estate allcoation is indexed to the home country, and thus the region is left blank. The last two columns of panel A show the difference of the total geographic allocation between the average SWF allocations and the capitalization and pension fund benchmarks.

Panel A: Average SWF Allocations (in percent of portfolio)

\begin{tabular}{lcccc|cc}
\hline & \multicolumn{5}{c|}{ SWF Allocations } & \multicolumn{2}{c}{ Excess over } & Excess over \\
Asia (excl Japan \& Middle East) & Public Equity Private Equity & Real Estate & Total & \multicolumn{2}{c}{ Capation Pension Fund } \\
\cline { 2 - 7 } Europe & 0.251 & 0.314 & 0.039 & 0.230 & 0.094 & 0.195 \\
Latin America & 0.327 & 0.161 & 0.053 & 0.227 & -0.113 & -0.012 \\
Middle East \& Africa & 0.011 & 0.000 & 0.001 & 0.006 & -0.051 & 0.001 \\
North America & 0.148 & 0.493 & 0.781 & 0.368 & 0.348 & 0.358 \\
Pacific & 0.208 & 0.016 & 0.095 & 0.130 & -0.164 & -0.370 \\
Total & 0.055 & 0.015 & 0.032 & 0.039 & -0.115 & -0.073 \\
Asset Class Total & 1.000 & 1.000 & 1.000 & 1.000 & & \\
\hline
\end{tabular}

Panel B: Benchmark Allocations (in percent of portfolio)

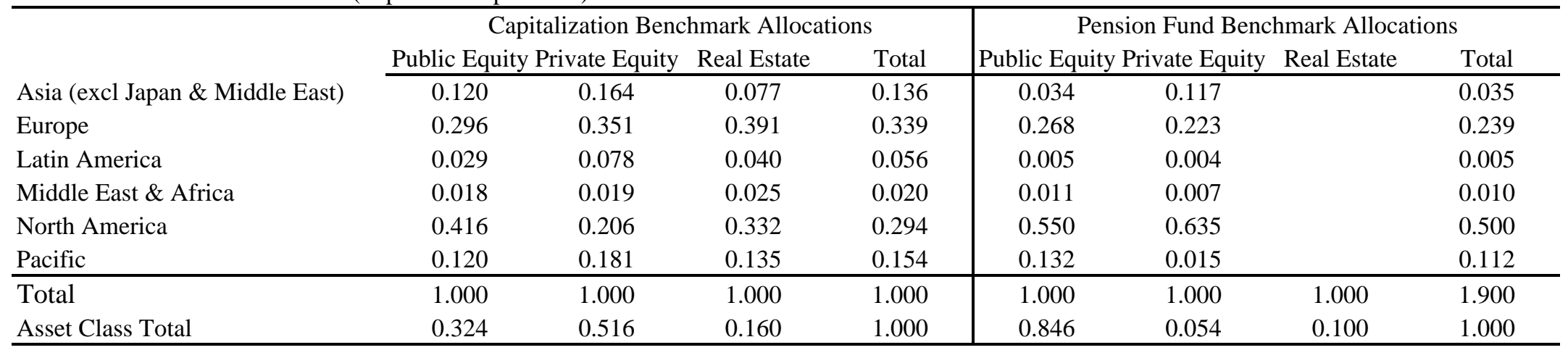


Table 5: Industry Breakdown of SWF and Benchmark Portfolio Allocations

Table A presents the equally weighted SWF portfolio allocations, where each SWF is based on its time series average. Panel $B$ reports allocations based on world market capitalization and large pension funds. The last two columns of panel A show the difference between the average SWF allocations and the capitalization and pension fund benchmarks.

Panel A: Average SWF Allocations (in percent of portfolio)

\begin{tabular}{|c|c|c|c|c|c|c|c|c|}
\hline \multirow{3}{*}{ Consumer Goods } & \multicolumn{4}{|c|}{ SWF Allocations } & \multirow{2}{*}{\multicolumn{2}{|c|}{$\begin{array}{c}\text { Excess over } \text { Excess over } \\
\text { Capitalization Pension Fund }\end{array}$}} & & \\
\hline & \multicolumn{2}{|c|}{ Public Equity Private Equity } & \multirow[t]{2}{*}{ Real Estate } & \multirow{2}{*}{$\frac{\text { Total }}{0.026}$} & & & & \\
\hline & 0.034 & 0.029 & & & -0.012 & -0.027 & & \\
\hline Consumer Services & 0.094 & 0.068 & & 0.069 & -0.264 & -0.034 & & \\
\hline Energy & 0.097 & 0.334 & & 0.148 & 0.114 & 0.064 & & \\
\hline Fabricated Products & 0.013 & 0.001 & & 0.007 & -0.019 & -0.027 & & \\
\hline Finance & 0.313 & 0.150 & & 0.207 & 0.100 & 0.011 & & \\
\hline Food & 0.028 & 0.011 & & 0.018 & 0.000 & -0.006 & & \\
\hline Healthcare & 0.048 & 0.011 & & 0.028 & -0.004 & -0.056 & & \\
\hline Materials & 0.054 & 0.078 & & 0.051 & -0.028 & -0.011 & & \\
\hline Real Estate & 0.001 & 0.000 & 1.000 & 0.188 & 0.012 & 0.087 & & \\
\hline Technology & 0.042 & 0.017 & & 0.027 & -0.014 & -0.058 & & \\
\hline Telecommunications & 0.118 & 0.039 & & 0.073 & 0.032 & 0.001 & & \\
\hline Transportation & 0.069 & 0.173 & & 0.086 & 0.060 & 0.071 & & \\
\hline Transportation Manufacturing & 0.036 & 0.041 & & 0.031 & 0.005 & -0.013 & & \\
\hline Utilities & 0.053 & 0.050 & & 0.042 & 0.019 & 0.000 & & \\
\hline Total & 1.000 & 1.000 & & 1.000 & & & & \\
\hline Asset Class Total & 0.520 & 0.292 & 0.188 & 2.000 & 0.0 & 0.0 & & \\
\hline \multicolumn{9}{|c|}{ Panel B: Benchmark Allocations (in percent of portfolio) } \\
\hline & \multicolumn{4}{|c|}{ Capitalization Benchmark Allocations } & \multicolumn{4}{|c|}{ Pension Fund Benchmark Allocations } \\
\hline & Public Equity & Private Equity & Real Estate & Total & Public Equity & Private Equity & Real Estate & Total \\
\hline Consumer Goods & 0.060 & 0.036 & & 0.038 & 0.059 & 0.058 & & 0.053 \\
\hline Consumer Services & 0.134 & 0.561 & & 0.333 & 0.113 & 0.135 & & 0.103 \\
\hline Energy & 0.082 & 0.013 & & 0.034 & 0.093 & 0.099 & & 0.084 \\
\hline Fabricated Products & 0.022 & 0.036 & & 0.026 & 0.039 & 0.020 & & 0.034 \\
\hline Finance & 0.199 & 0.082 & & 0.107 & 0.219 & 0.184 & & 0.196 \\
\hline Food & 0.028 & 0.018 & & 0.018 & 0.027 & 0.031 & & 0.024 \\
\hline Healthcare & 0.082 & 0.010 & & 0.032 & 0.094 & 0.102 & & 0.085 \\
\hline Materials & 0.071 & 0.107 & & 0.079 & 0.069 & 0.064 & & 0.062 \\
\hline Real Estate & 0.012 & 0.024 & 1.000 & 0.176 & 0.001 & 0.007 & 1.000 & 0.102 \\
\hline Technology & 0.087 & 0.025 & & 0.041 & 0.094 & 0.090 & & 0.084 \\
\hline Telecommunications & 0.106 & 0.013 & & 0.041 & 0.079 & 0.096 & & 0.072 \\
\hline Transportation & 0.022 & 0.037 & & 0.026 & 0.016 & 0.021 & & 0.015 \\
\hline Transportation Manufacturing & 0.046 & 0.021 & & 0.026 & 0.049 & 0.044 & & 0.044 \\
\hline Utilities & 0.047 & 0.015 & & 0.023 & 0.047 & 0.048 & & 0.043 \\
\hline Total & 1.000 & 1.000 & & 1.000 & 1.000 & 1.000 & & 1.000 \\
\hline Asset Class Total & 0.324 & 0.516 & 0.160 & 1.000 & 0.846 & 0.054 & 0.100 & 1.000 \\
\hline
\end{tabular}


Table 6: How Well do Financial Investor Variables Explain SWF Portfolios?

The dependent variable is the SWF portfolio weight for 20 SWFs to public or private equity in one of 13 industries or to real estate in one of 7 regions or to real estate for all available years 1999-2008. The mean number of years in the sample is 6 years. Cap Benchmark and Pension Benchmark are the portfolio allocation weights based on total capitalization and CEM pension funds, respectively. The mean weight variable is the mean weight to the asset class (private equity, public equity and real estate) for these benchmarks. Cov(FiscalRevenues, Bin Returns) is a 19 year rolling covariance of the SWF country fiscal revenue returns with returns for the industry-geography. Fixed Income is the value of foreign reserves plus SWF fixed income divided by the SWF value plus foreign reserves.

StDev(Fiscal Revenues) is the standard deviation of home country fiscal revenue dollars. Standard errors are clustered at the SWF level in all columns except 3, in which a GLS -AR1 estimation uses the Prais Winsten procedure. Column 4 excludes real estate. Columns 5 and 6 are within public equites and private equities respectively. ${ }^{* *},{ }^{* *}$, and $*$ denote significance at the $1 \%, 5 \%$ and $10 \%$ levels respectively.

\begin{tabular}{|c|c|c|c|c|c|c|}
\hline & 1 & 2 & 3 & 4 & 5 & 6 \\
\hline & & & & & Within & Within \\
\hline & & & & No Real & Public & Private \\
\hline Dependent Variable: SWF Portfolio & Teight X 100 & & & Estate & Equities & Equity \\
\hline & Cluster & Cluster & GLS - AR1 & Cluster & Cluster & Cluster \\
\hline Pension: Asset Class Mean Weight & $55.00^{* *}$ & $56.06^{* *}$ & $39.22^{* * *}$ & $156.3^{* * *}$ & & \\
\hline & [20.33] & [20.63] & {$[7.768]$} & {$[53.08]$} & & \\
\hline Pension Benchmark Weight & $54.14 * * *$ & $54.13^{* * *}$ & $46.98 * * *$ & $30.12^{* *}$ & $35.82 * * *$ & $-8.332 *$ \\
\hline & [13.75] & [13.79] & {$[2.378]$} & [11.24] & [11.12] & [4.010] \\
\hline Cap: Asset Class Mean Weight & $107.3^{* *}$ & $107.6^{* *}$ & $88.42 * * *$ & $241.9^{* *}$ & & \\
\hline & [48.48] & [48.25] & {$[7.780]$} & {$[87.73]$} & & \\
\hline Cap Benchmark Weight & $-10.11 *$ & $-10.50 * *$ & $-12.00 * * *$ & $-3.938 * *$ & & \\
\hline & {$[4.870]$} & [4.816] & [2.343] & {$[1.410]$} & & \\
\hline Fixed Income*Beta & & $0.014^{*}$ & $0.013^{* * *}$ & $0.016^{* *}$ & 0.041 & 0.015 \\
\hline & & {$[0.007]$} & {$[0.005]$} & {$[0.006]$} & {$[0.030]$} & [0.015] \\
\hline Wealth*Beta & & -0.003 & -0.010 & 0.005 & -0.004 & 0.017 \\
\hline & & {$[0.012]$} & {$[0.025]$} & {$[0.012]$} & [0.041] & {$[0.029]$} \\
\hline St Dev (Fiscal Revenues) * Beta & & $-0.016^{*}$ & -0.012 & $-0.016^{*}$ & -0.014 & 0.005 \\
\hline & & [0.009] & {$[0.016]$} & {$[0.009]$} & [0.037] & [0.117] \\
\hline Cov (Fiscal Revenues, Bin Returns) & & 0.026 & 0.370 & -1.003 & 0.304 & 0.813 \\
\hline & & [1.197] & [2.617] & {$[0.646]$} & [3.087] & [4.053] \\
\hline PE Weight in Industry-Region & & & & & $0.221^{*}$ & \\
\hline & & & & & {$[0.120]$} & \\
\hline Alternatives \% Portfolio * Beta & & & & & $0.0034^{* *}$ & \\
\hline & & & & & {$[0.0016]$} & \\
\hline Constant & -0.563 & -0.587 & $-0.349 * * *$ & $-1.663 * *$ & $0.516^{* * *}$ & $1.150^{* * *}$ \\
\hline & {$[0.355]$} & {$[0.358]$} & {$[0.070]$} & {$[0.679]$} & {$[0.101]$} & {$[0.075]$} \\
\hline Observations & 23247 & 23247 & 23247 & 22386 & 11193 & 7917 \\
\hline R-squared & 0.072 & 0.072 & 0.029 & 0.027 & 0.025 & 0.001 \\
\hline Rho & & & 0.881 & & & \\
\hline
\end{tabular}




\section{Table 7: How Well do Financial Investor \& State Planner Variables Explain SWF Portfolios?}

The dependent variable is the SWF portfolio weight for 20 SWFs to public or private equity in one of 13 industries or to real estate in one of 7 regions or to real estate for all available years 1999-2008. The mean number of years in the sample is 6 years. The financial investor variables are the same as defined in Table 6. Measures to capture state planner objectives include Strategic Plan, which takes a value of 1 if the industry is mentioned in the country's strategic plan, Perceived Market Failure, which is the OECD measure of anticompetitive regulation inpact in inputs to a sector, and Perceived Skill, which is the proportion of domestic investment invested in that industry with control (>20\% stake). Standard errors are clustered at the SWF level in all columns except 3, in which a GLS -AR1 estimation uses the Prais Winsten procedure. Column 6 excludes real estate. Columns 7 and 8 are within public equites and private equities respectively. $* * * * *$, and $*$ denote significance at the $1 \%, 5 \%$ and $10 \%$ levels respectively.

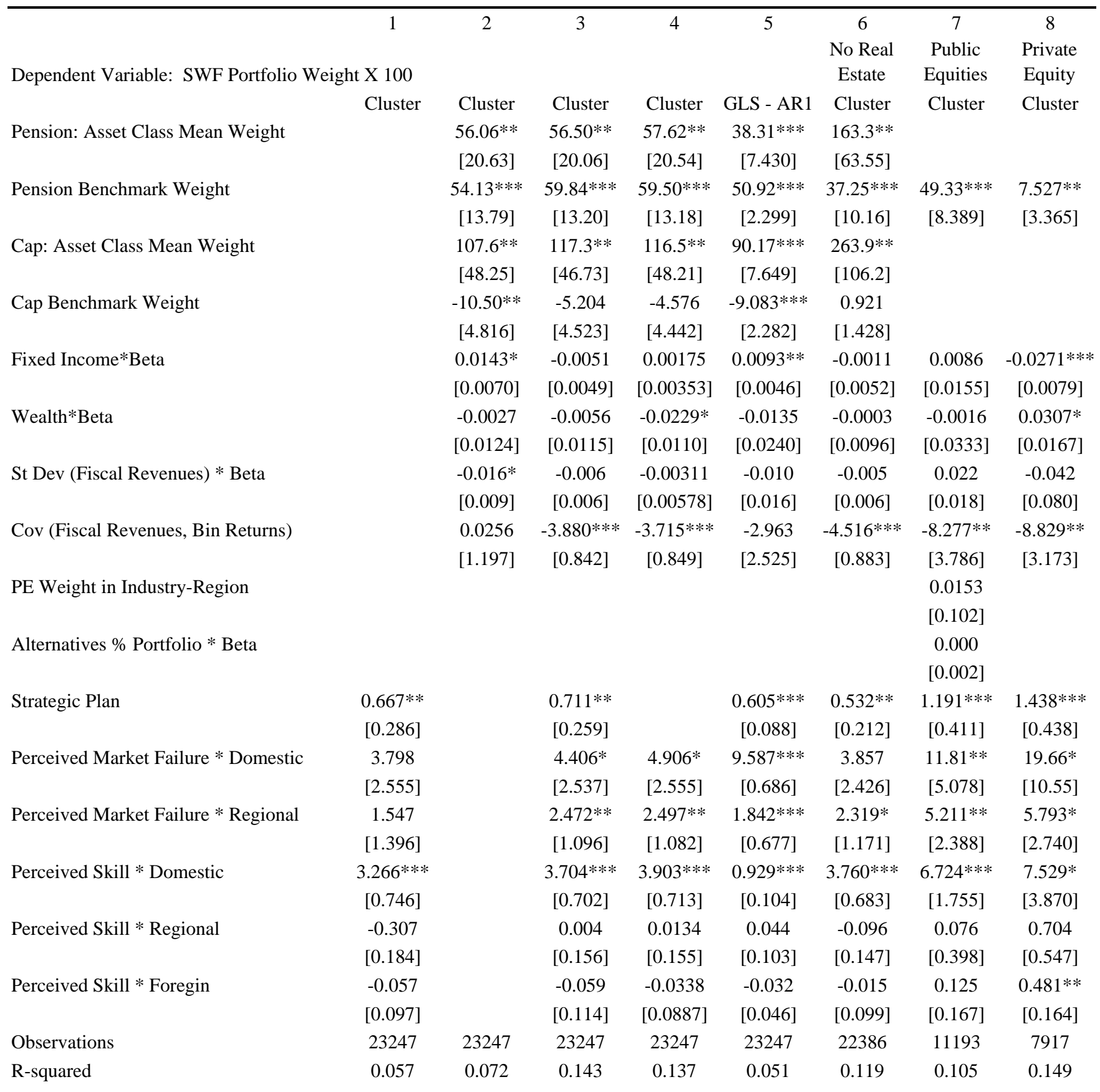




\section{Table 8: Ownership Stakes' Relationship to Objectives}

The dependent variable is a SWF's average ownership stake for a geography-asset class-industry bin, where a bin has a positive stake. Stakes held in index funds are assumed to have 0.00075 ownership, the average holding of the Norwegian Global Fund.The first three columns are estimated with OLS, clustered standard errors at the SWF level. Columns 4-6 are estimated with GLS-AR1. The independent variables are the overall SWF R-square as pictured in Figure 1 and explained in the heterogeneity section of the text and the fraction of r-square identified by the state planner variables over r-square of the financial plus state planner variables. Standard errors are in brackets. ***, **, and * denote significance at the $1 \%$, $5 \%$ and $10 \%$ levels respectively.

\begin{tabular}{|c|c|c|c|c|c|c|}
\hline \multicolumn{7}{|c|}{ Dependent Variable: Average Ownership Stake in Region-Industry Asset Class Bin } \\
\hline & 1 & 2 & 3 & 4 & 5 & 6 \\
\hline Overall SWF R-Square & $\begin{array}{c}-0.0268 \\
{[0.0187]}\end{array}$ & $\begin{array}{c}-0.0484 * * \\
{[0.0231]}\end{array}$ & $\begin{array}{c}-0.0483 * * \\
{[0.0229]}\end{array}$ & $\begin{array}{l}-0.0268^{*} \\
{[0.0161]}\end{array}$ & $\begin{array}{c}-0.0385 * * * \\
{[0.0144]}\end{array}$ & $\begin{array}{c}-0.0389 * * * \\
{[0.0143]}\end{array}$ \\
\hline Fraction Explained by State Planner & $\begin{array}{c}0.0082 * * \\
{[0.0034]}\end{array}$ & $\begin{array}{c}0.0058 * \\
{[0.0030]}\end{array}$ & $\begin{array}{c}0.0058^{*} \\
{[0.0030]}\end{array}$ & $\begin{array}{c}0.0067 * * * \\
{[0.0019]}\end{array}$ & $\begin{array}{c}0.0040 * * \\
{[0.0017]}\end{array}$ & $\begin{array}{c}0.0041^{* *} \\
{[0.0017]}\end{array}$ \\
\hline Observations & 11874 & 11874 & 11874 & 11874 & 11874 & 11874 \\
\hline R-Square & 0.351 & 0.483 & 0.487 & 0.203 & 0.281 & 0.284 \\
\hline Asset Class Fixed Effects & $\mathrm{Y}$ & Y & Y & Y & $\mathrm{Y}$ & $\mathrm{Y}$ \\
\hline Region Fixed Effects & $\mathrm{N}$ & $\mathrm{Y}$ & $\mathrm{Y}$ & $\mathrm{N}$ & $\mathrm{Y}$ & Y \\
\hline Industry Fixed Effects & $\mathrm{N}$ & $\mathrm{N}$ & Y & $\mathrm{N}$ & $\mathrm{N}$ & $\mathrm{Y}$ \\
\hline Estimation Method & & luster by SW & & GLS-AR1 & GLS-AR1 & GLS-AR1 \\
\hline rho for AR1 & & & & 0.924 & 0.908 & 0.907 \\
\hline
\end{tabular}

